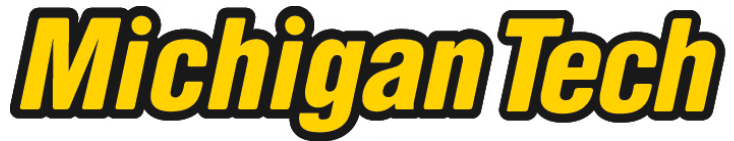 \\ Michigan Technological University Create the Future Digital Commons @ Michigan Tech
}

Dissertations, Master's Theses and Master's Reports - Open

Dissertations, Master's Theses and Master's

Reports

2011

Cladophora, mass transport, and the nearshore phosphorus shunt

Aaron I. Dayton

Michigan Technological University

Follow this and additional works at: https://digitalcommons.mtu.edu/etds

Part of the Civil and Environmental Engineering Commons

Copyright 2011 Aaron I. Dayton

\section{Recommended Citation}

Dayton, Aaron I., "Cladophora, mass transport, and the nearshore phosphorus shunt ", Master's Thesis, Michigan Technological University, 2011.

https://doi.org/10.37099/mtu.dc.etds/228

Follow this and additional works at: https://digitalcommons.mtu.edu/etds

3 Part of the Civil and Environmental Engineering Commons 


\title{
CLADOPHORA, MASS TRANSPORT, AND THE NEARSHORE PHOSPHORUS SHUNT
}

By

Aaron I. Dayton

\begin{abstract}
A THESIS
Submitted in partial fulfillment of the requirements for the degree of MASTER OF SCIENCE

(Environmental Engineering Science)

MICHIGAN TECHNOLOGICAL UNIVERSITY

2011
\end{abstract}

(C2011 Aaron I. Dayton 
This thesis, "Cladophora, Mass Transport, and the Nearshore Phosphorus Shunt," is hereby approved in partial fulfillment of the requirements for the Degree of MASTER OF SCIENCE IN ENVIRONMENTAL ENGINEERING SCIENCE.

Department of Civil and Environmental Engineering

Signatures:

Thesis Advisor

Dr. Martin T. Auer

Department Chair

Dr. David W. Hand

Date 


\section{Contents}

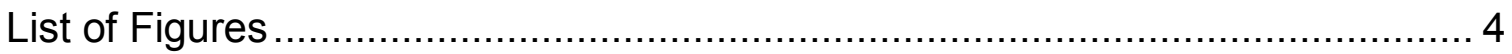

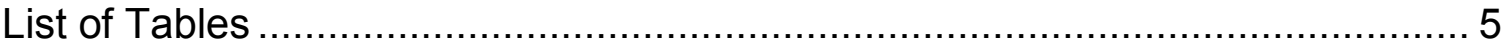

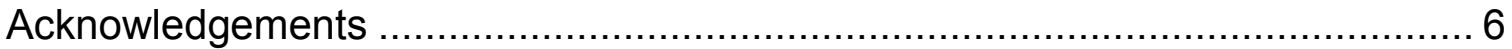

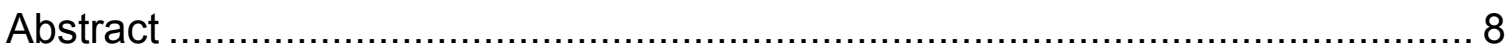

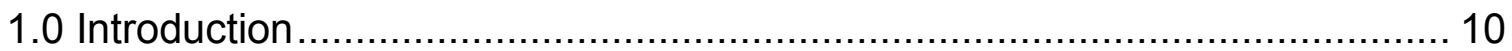

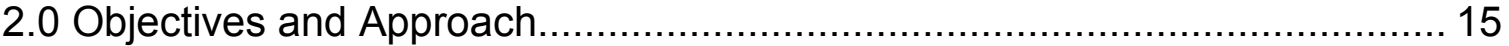

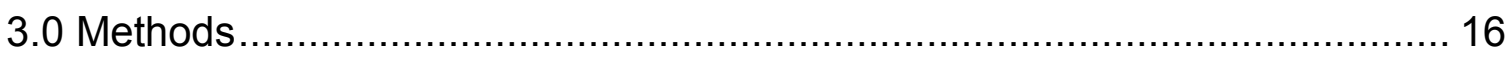

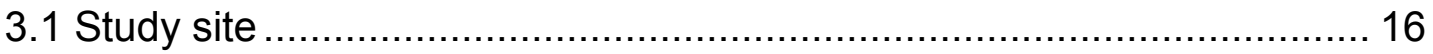

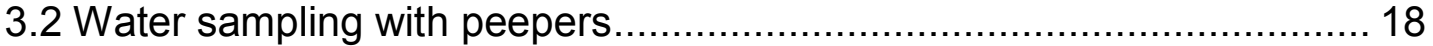

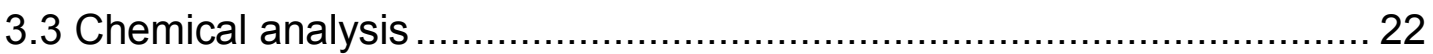

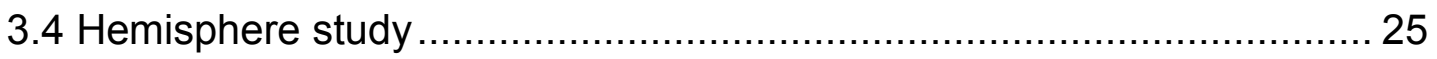

3.5 Meteorology and mass transport profiling ........................................ 25

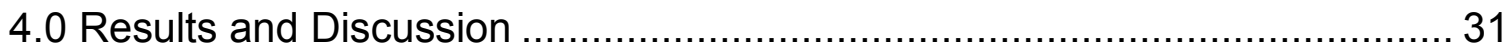

4.1 Mussel phosphorus excretion potential............................................ 31

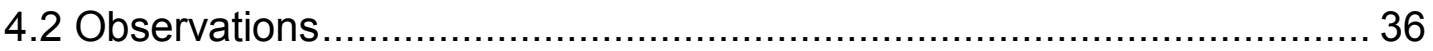

4.2.1 Impact of mussel density on boundary layer concentrations ........ 38

4.2.2 Impact of wind speed on boundary layer concentrations ............ 40

4.2.3 Impact of quiescent period on boundary layer concentrations ..... 40

4.3 Relating boundary layer profiles to meteorological conditions ............... 43

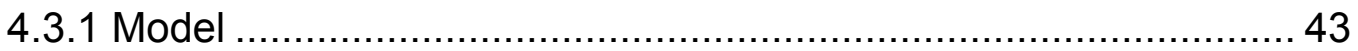

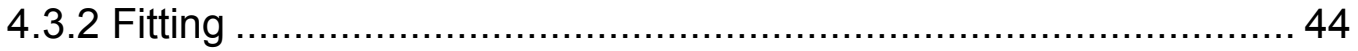

4.3.3 Flux and duration of quiescent conditions ............................... 45

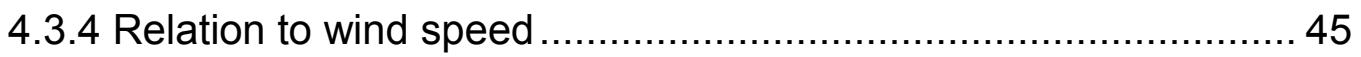

5.0 Summary, Conclusion and Implications for Management........................... 53

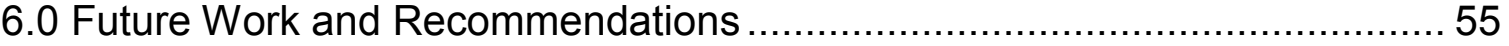

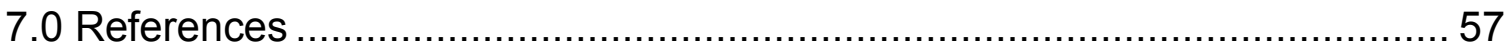

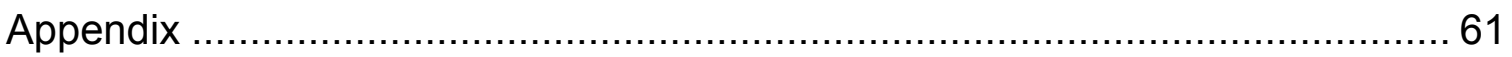




\section{List of Figures}

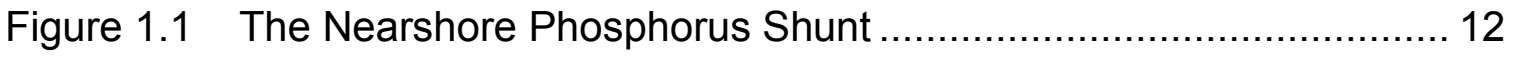

Figure 3.1 Low and high density sites: Good Harbor Bay in Lake Michigan .... 17

Figure 3.2 Modified Hesslein Sampler (peeper): close-up of cells............... 19

Figure 3.3 Sampler deployed over Cladophora and mussel bed............... 20

Figure 3.4 Equilibration of a peeper containing fluorescein dye ................... 21

Figure 3.5 Standard curve for soluble reactive phosphorus ......................... 23

Figure 3.6 Standard curve for detection limit calculation .............................. 24

Figure 3.7 Diver setting up dome for mussel P excretion potential study ...... 26

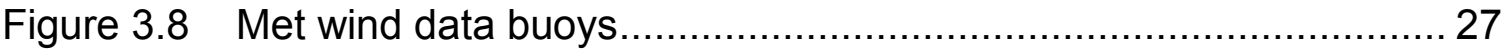

Figure 3.9 Wind speeds and current velocities ........................................ 28

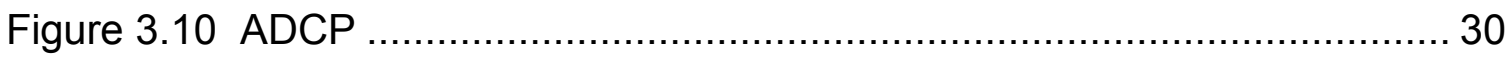

Figure 4.1 Production of Cladophora as a function of SRP concentration ....... 32

Figure 4.2 Boundary conditions 1, 4, and 7 meters above the lake bottom..... 34

Figure 4.3 SRP conc. over mussels under dome ....................................... 35

Figure 4.4 Peeper profiles of SRP concentrations collected June-Aug, 2011 . 37

Figure 4.5a Mussel density: model predicted profiles ..................................... 39

Figure 4.5b Mussel density: observed peeper profiles .................................. 39

Figure 4.6a Wind speed: model predicted profiles......................................... 41

Figure 4.6b Wind speed: observed peeper profiles ..................................... 41

Figure 4.7a Duration of quiescent period: model predicted profiles.................. 42

Figure 4.7b Duration of quiescent period: observed peeper profiles ................ 42

Figure 4.8 Calibrated peeper data and model: LMD quiescent....................... 46

Figure 4.9 Calibrated peeper data and model: HMD quiescent ..................... 47

Figure 4.10 Calibrated peeper data and model: turbulent ............................. 48

Figure 4.11 SRP flux vs. duration of quiescent period .................................. 49

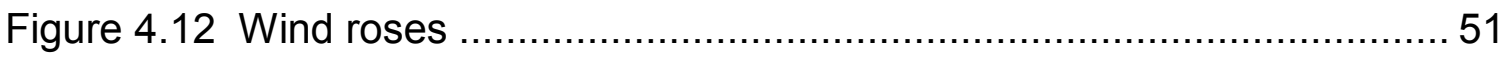

Figure 4.13 Model calibrated to the diffusion coefficient................................. 52

Figure 6.1 SRP mass transport, mussel excretion and Cladophora uptake .... 56

Figure A.1 Collection of water samples from peeper ................................... 63 


\section{List of Tables}

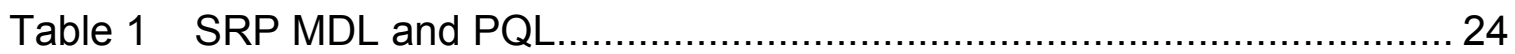




\section{Acknowledgments}

The valuable experiences I have had throughout my master's coursework and research would not have been possible had it not been for the numerous people who donated extremely generous amounts of time in assisting me with my research and studies.

I would first like to thank my father and mother who instilled in me and my sister, at an early age, a passion for exploring and understanding the world around us.

I would also like to thank my friends and research mates Renn Lambert, Rasika Gawde, Marcel Dijkstra and Sue Larson. Working with this wonderful group of people was both intellectually stimulating and, perhaps more importantly, fun.

Thank you Hans VanSumeran and the rest of the Northwestern Michigan College crew as well as the Michigan Tech Research Institute and the National Park Service. This project would not have been possible had it not been for your assistance in site location selection and boat assistance.

To captains Tony Radjenovich, Mike Grovenor, Bob Schlitts, and Jeff Godi as well as divers Chris Doyal, Alisa Kroupa, Ross Richardson, Mike Garner, and Bill Giorgis for providing boat assistance and diver support under windy and quiescent conditions at a moment's notice. 
Thank you Dave Perram for your help in the laboratory for both this research as well as my teaching assistantships.

To Jesse Nordeng and Rob Fritz for your vision and willingness to work late to meet stringent project deadlines.

To the excellent modeler and collaborator, Dr. Joe Atkinson. Thank you for all your help throughout the model development stages.

Thanks to my committee members Dr. Paul Doskey and Colin Brooks for your expertise and insight during my thesis defense and review process.

To the plethora of professors, classmates and friends at Michigan Tech who have been excellent mentors and role models as I worked to bridge the gap between science and engineering.

To my excellent advisor - Dr. Martin Auer. He pushed me to bring out my very best and I cannot express enough gratitude. Our numerous late night phone conversations throughout the summer made this challenging project possible. I could not have asked for a better advisor to help me develop as an engineer, scientist and individual. Thank you Dr. Auer. 


\section{Abstract}

Excessive Cladophora growth in the Great Lakes has led to beach fouling and the temporary closure of nuclear power plants and has been associated with avian botulism and the persistence of human pathogens. As the growth-limiting nutrient for Cladophora, phosphorus is the appropriate target for management efforts. Dreissenids (zebra and quagga mussels) have the ability to capture particulate phase phosphorus (otherwise unavailable to Cladophora) and release it in a soluble, available form. The significance of this potential nutrient source is, in part, influenced by the interplay between phosphorus flux from the mussel bed and turbulent mixing in establishing the phosphorus levels to which Cladophora is exposed. It is hypothesized that under quiescent conditions phosphorus will accumulate near the sediment-water interface, setting up vertical phosphorus gradients and favorable conditions for resource delivery to Cladophora. These gradients would be eliminated under conditions of wind mixing, reducing the significance of the dreissenid-mediated nutrient contribution.

Soluble reactive phosphorus (SRP) levels were monitored over dreissenid beds (densities on the order of $350 \cdot \mathrm{m}^{-2}$ and $3000 \cdot \mathrm{m}^{-2}$ ) at a site $8 \mathrm{~m}$ deep in Lake Michigan. Monitoring was based on the deployment of Modified Hesslein Samplers which collected samples for SRP analysis over a distance of $34 \mathrm{~cm}$ above the bottom in $2.5 \mathrm{~cm}$ intervals. Deployment intervals were established to capture a wind regime (calm, windy) that persisted for an interval consistent with the sampler equilibration time of 7 hours. Results indicate that increased mussel density leads to an increased concentration boundary layer; increased wind 
speed leads to entrainment of the concentration boundary layer; and increased duration of quiescent periods leads to an increased concentration boundary layer. This concentration boundary layer is of ecological significance and forms in the region inhabited by Cladophora. 


\subsection{Introduction}

The Great Lakes Water Quality Agreement of 1972 (renewed in 1978) specifically referenced conditions of nuisance algal biomass in Lakes Erie, Michigan, and Ontario and set target phosphorus $(\mathrm{P})$ loads to reduce or eliminate those conditions. While this goal appears to have been met for offshore waters (Dove 2009), it has been concluded that the Agreement has not adequately addressed nearshore eutrophication issues (Agreement Review Committee 2006). Contemporary concerns relating to nuisance conditions in the nearshore focus on harmful algal blooms (HABs, typically cyanobacteria; Anderson et al. 2002) and the filamentous, green alga, Cladophora (Higgins 2008; Auer et al. 2010). HABs, increasingly associated with nutrient enrichment, can lead to alteration of aquatic habitat, fish, mammal and seabird mortality and human illness (Anderson et al. 2002; Dyble et al. 2008). Cladophora grows to nuisance proportions in the nearshore waters of the Great Lakes, leading to beach fouling and the temporary closure of nuclear power plants and has been associated with avian botulism (New York Sea Grant and Pennsylvania Sea Grant 2001) and the persistence of human pathogens (Byappanahalli et al. 2003).

In the nearshore waters of the Great Lakes, Cladophora grows to depths mediated by light availability wherever solid substrate is present and the nutrients required to support growth are available (Hecky et al. 2004). Cladophora has been known to be in the Great Lakes at least since the early 1800s, with nuisance growth reported in the early 1970s (Taft and Kishler 1973). Monitoring, experimental studies and modeling of Cladophora in the 1980s (see Auer 1982 
and papers therein) supported successful management efforts to control nuisance conditions (Painter and Kamaitis 1987). Attention to Cladophora waned in subsequent years but has achieved a higher level of visibility recently (Auer et al. 2010).

As the limiting nutrient for Cladophora, phosphorus is the appropriate target for management efforts (Auer et al. 1982; Higgins et al. 2005). Phosphorus mediation of Cladophora growth can occur on a whole-lake, regional or local scale. For example, Lakes Erie and Ontario have historically been considered to be whole-lake driven (DePinto et al.1978), the coastal zone of western Lake Michigan impacted by large river discharges (Greb et al. 2004) and nearshore Lake Huron by local nutrient sources (Canale and Auer 1982). Thus, management efforts have focused on reducing soluble reactive phosphorus levels (Lee 1980; Arnott and Vanni 1995) at the appropriate geographical scale.

The establishment of zebra and quagga mussels in the Great Lakes has resulted in a reconsideration of Cladophora management (Hecky et al. 2004). Mussels can impact Cladophora by providing hard substrate for attachment (Wilson et al. 2006), increasing light penetration (Holland 1993; Howell et al. 1996; Auer et al. 2010) and altering pathways of phosphorus cycling. With respect to phosphorus, mussels, acting in the role of ecosystem engineers (Coleman and Williams 2002) alter nutrient cycling pathways. It is well understood that dreissenids ingest particulate phosphorus and excrete the soluble phosphorus required for algal uptake (Conroy et al. 2005). Hecky et al. (2004) coined the phrase "nearshore phosphorus shunt" to describe the process 
by which mussels capture particulate phosphorus (terrigenous solids and phytoplankton) otherwise unavailable to Cladophora, and release it in a soluble form (Figure 1.1). Through this process, mussels retain, recycle and deliver watershed-derived P to nearshore waters inhabited by Cladophora (Hecky et al. 2004). Dreisseinids act similarly in filtering phytoplankton from the water column, both recycling $P$ for use by Cladophora (Hecky et al. 2004) and eliminating a source of nutrient competition with the attached alga (Fahnenstiel et al. 1995).
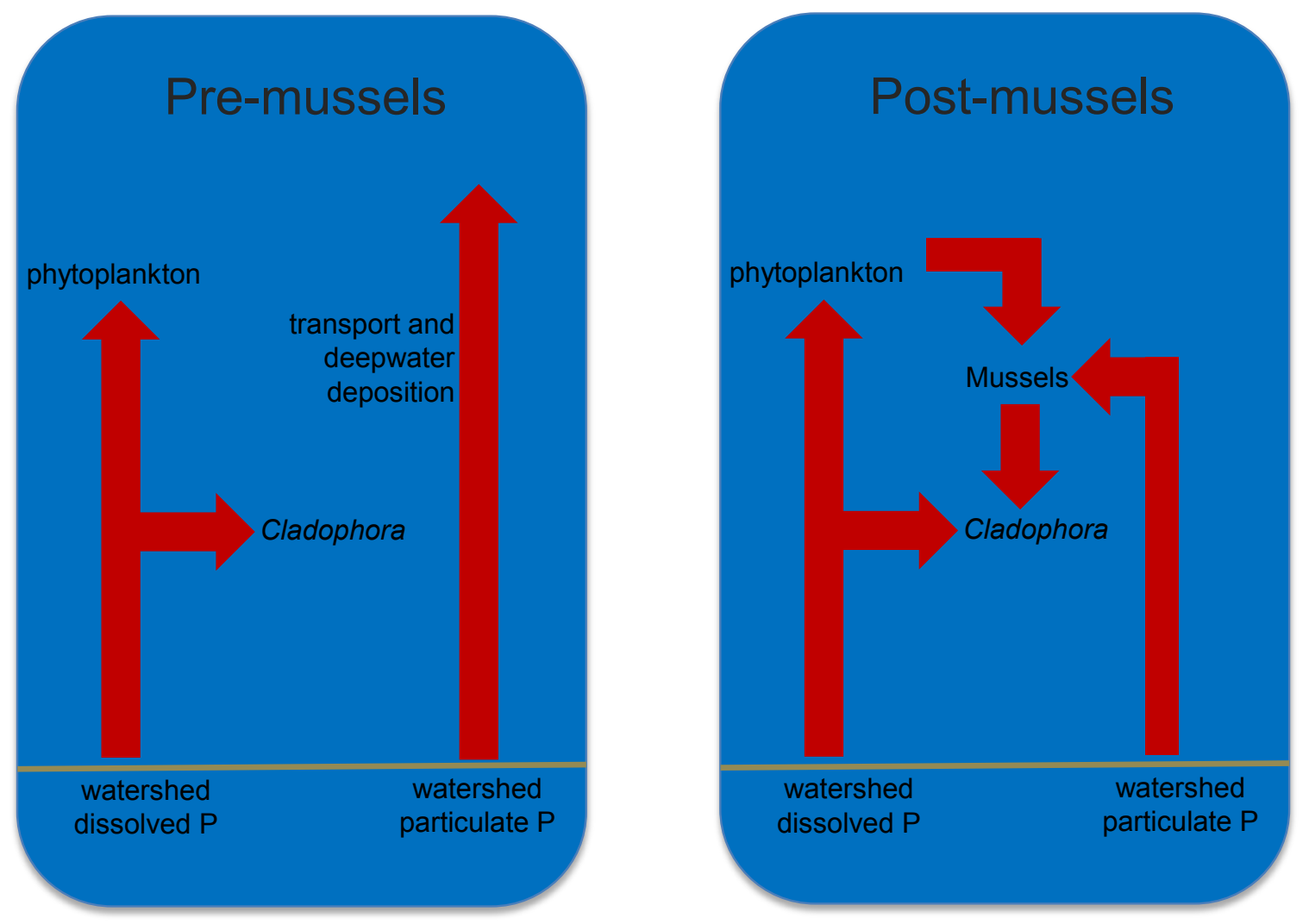

Figure 1.1: The Nearshore Phosphorus Shunt. 
Mussel excretion of phosphorus has been regularly invoked as supporting nuisance growth of Cladophora (Dove 2009; Malkin et al. 2010; Depew et al. 2011; Higgins et al. in review). However, conclusions that mussels lie at the root of the Cladophora problem have been correlative in nature and have no mechanistic basis. It is not denied that phosphorus excretion by dreissenids is of potential importance to Cladophora. Ozersky et al. (2009) performed measurements and calculations demonstrating that mussel phosphorus fluxes are comparable to and may exceed the growth requirement of Cladophora. However, rates of phosphorus uptake by algae are dictated by water column $\mathrm{P}$ levels, and only indirectly related to fluxes from mussels and other sources. Thus quantification of the impacts of the nearshore phosphorus shunt requires that fluxes from mussels and uptake by Cladophora be linked through a mechanistic treatment of mass transport as it mediates water column $\mathrm{P}$ concentrations and thus the ecological significance of the nearshore phosphorus shunt.

Relationships between mass transport and mussel activity have been observed in several studies conducted on the Great Lakes. For example, Ackerman et al. (2001) observed depletion of chlorophyll and organic seston in waters overlying a zebra mussel bed in Lake Erie, attributing the phenomenon to semidiurnal stratification and attendant reductions in turbulent mixing. Boegman et al. (2008) further demonstrated through modeling analysis that weak diurnal stratification, developing under calm conditions (wind $<6 \mathrm{~m} \cdot \mathrm{s}^{-1}$ ), was sufficient to suppress vertical mixing and permit development of a concentration boundary layer (here with depleted seston levels) above the mussel bed. This boundary 
layer was then entrained and destroyed as wind speeds rose above $6 \mathrm{~m} \cdot \mathrm{s}^{-1}$, restoring the supply of particulate matter to the benthos. The concept of near bottom particulate matter depletion through formation of a boundary layer may be extended as well to accumulation of soluble phosphorus under similarly quiescent conditions. Here, phosphorus excreted from mussel beds would accumulate within a concentration boundary layer formed above the mussel bed. Under turbulent conditions vertical mixing would destroy the boundary layer and phosphorus would be uniformly distributed throughout the water column. Quantification of vertical mixing over substrates supporting Cladophora and mussels is needed to quantitatively and mechanistically describe the relationship between estimates of dreissenid $P$ flux (Ozersky et al. 2009) and the ambient $P$ levels driving Cladophora growth (Auer and Canale 1982). 


\subsection{Objectives and Approach}

The objective of this research is to document the presence/absence of a soluble reactive phosphorus concentration boundary layer over mussel beds and to quantify the effects of mass transport (i.e. turbulent vs. quiescent conditions) in mediating nutrient supply to Cladophora. Soluble reactive phosphorus concentration profiles are measured above mussel beds over a range of mixing conditions using modified Hesslein samplers (peepers). Weather data and vertical mixing profiles (ADCP instrumentation) were collected as well. A vertical mass transport model was then applied to simulate phosphorus profiles and the model was calibrated and confirmed using the data obtained through peeper deployment. 


\subsection{Methods}

\subsection{Study Site}

The study was conducted in the Lake Michigan nearshore, at Good Harbor Bay near Leland, Michigan (Figure 3.1; 44’58.367, 85'49.716). The site offers high mussel densities and exposure to a broad range of mass transport conditions that make it representative of the Great Lakes ecosystem. Good Harbor Bay lies in close proximity to the Sleeping Bear Dunes National Lakeshore, recently voted "America's Most Beautiful Place" by NBC's "Good Morning America." Degradation of the site's beaches by nuisance growth of Cladophora has drawn the attention of scientists and agency officials. In addition, activity at this site offered opportunities to collaborate with other organizations including the Michigan Tech Research Institute, Northwestern Michigan College, the National Park Service and the United States Geological Survey.

The criterion for a specific monitoring location was that it have a depth capable of supporting Cladophora growth (light environment) as well as exposure to mass transport that would permit both formation (quiescent conditions) and destruction (turbulent conditions) of a concentration boundary layer. A site was selected which was similar to that found optimal for studies of boundary layer effects by Boegman et al. (2008), i.e. $8 \mathrm{~m}$ deep and hosting populations of zebra and quagga mussels. Low and high density mussel sites were selected within Good Harbor Bay (Figure 3.1; 44 $59^{\prime} 25^{\prime \prime} \mathrm{N}, 8^{\circ} 47^{\prime} 12^{\prime \prime} \mathrm{W}$ and $44^{\circ} 58^{\prime} 91^{\prime \prime} \mathrm{N}$, 


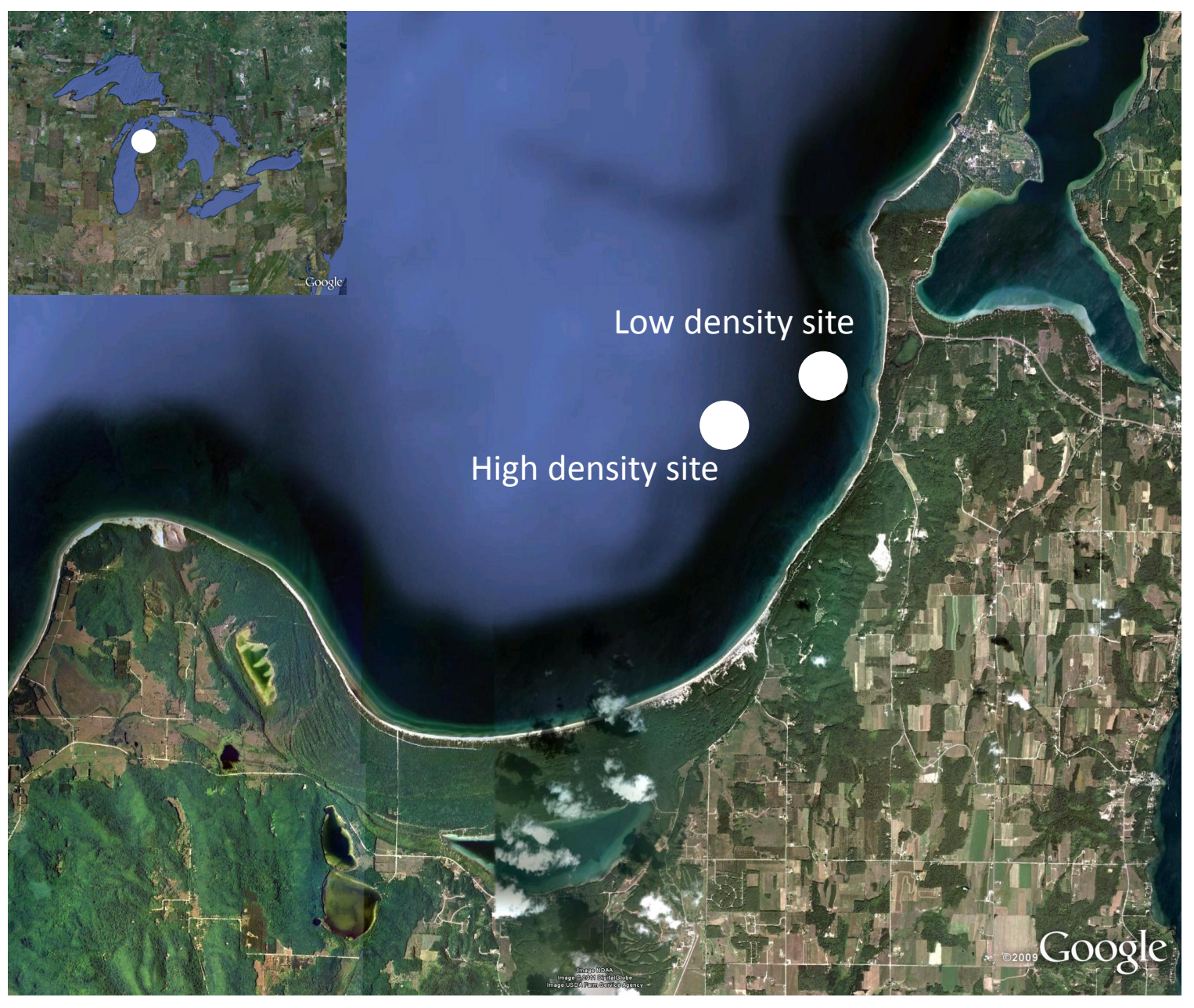

Figure 3.1: Low and high density mussel sites within Good Harbor Bay, Lake Michigan (modified from Google Earth). Inset: Good Harbor Bay in Lake Michigan (modified from Google Earth). 
$85^{\circ} 48^{\prime} 39^{\prime \prime} \mathrm{W}$, respectively). Mussels at the high density site were distributed in a continuous bed on hard, rocky substrate with abundances averaging $\sim 3000 \mathrm{~m}^{-2}$. In contrast, mussels at the low density site were distributed in clumps over sand with isolated logs and rocks and had abundances of only $\sim 350 \cdot \mathrm{m}^{-2}$. Although divers frequently deployed the water sampler, it was important that the study site have mussel beds of a size sufficient to accommodate deployment without the aid of divers, yet insure that the device was positioned over an active population of dreissenids.

\subsection{Water Sampling with Peepers}

Modified Hesslein Samplers (peepers, Figure 3.2) were constructed from a base unit available from Rickly Hydrological Company. As configured here, the peeper had 14 sample cells distributed at $2.5 \mathrm{~cm}$ intervals over the $34 \mathrm{~cm}$ height of the device. A polycarbonate membrane (0.4 micron, Sterlitech, Inc.) was placed on both sides of the peeper to separate the cells from the ambient environment while minimizing the barrier to mass transport (Figure 3.3). A dye study was conducted to determine the time required for peeper cells to equilibrate to the external (ambient) environment. Equilibrium was reached in 56 hours (Figure 3.4) and thus a minimum deployment time of 7 hours was established. Peeper cells were filled with milli-Q water, sealed with Teflon caps and deployed at the sites described above. The devices were harvested following exposure to a stable wind regime (quiescent, $<6 \mathrm{~m} \cdot \mathrm{s}^{-1} \rightarrow$ turbulent, $\geq 6$ $\mathrm{m} \cdot \mathrm{s}^{-1}$; Boegman et al. 2008) persisting for the required equilibration period. 


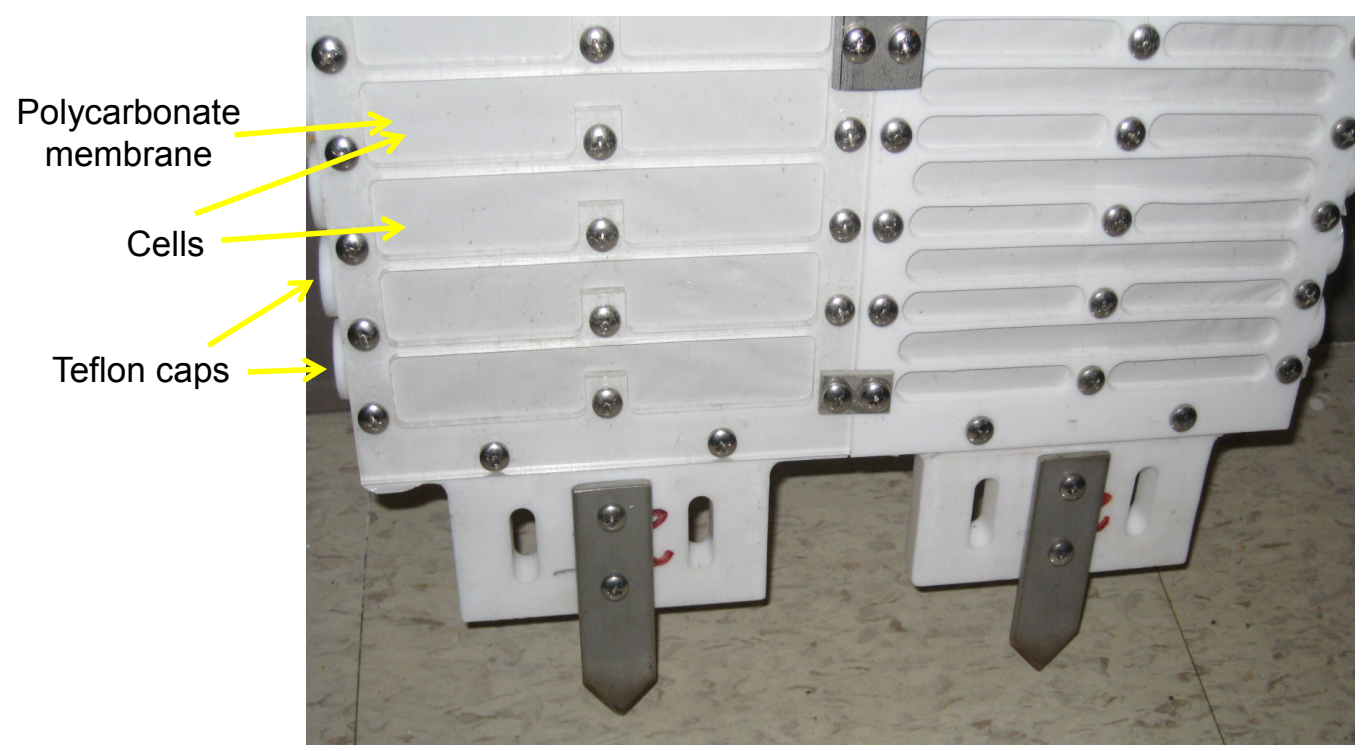

Figure 3.2: Modified Hesslein Sampler (peeper): Close-up of cells. 


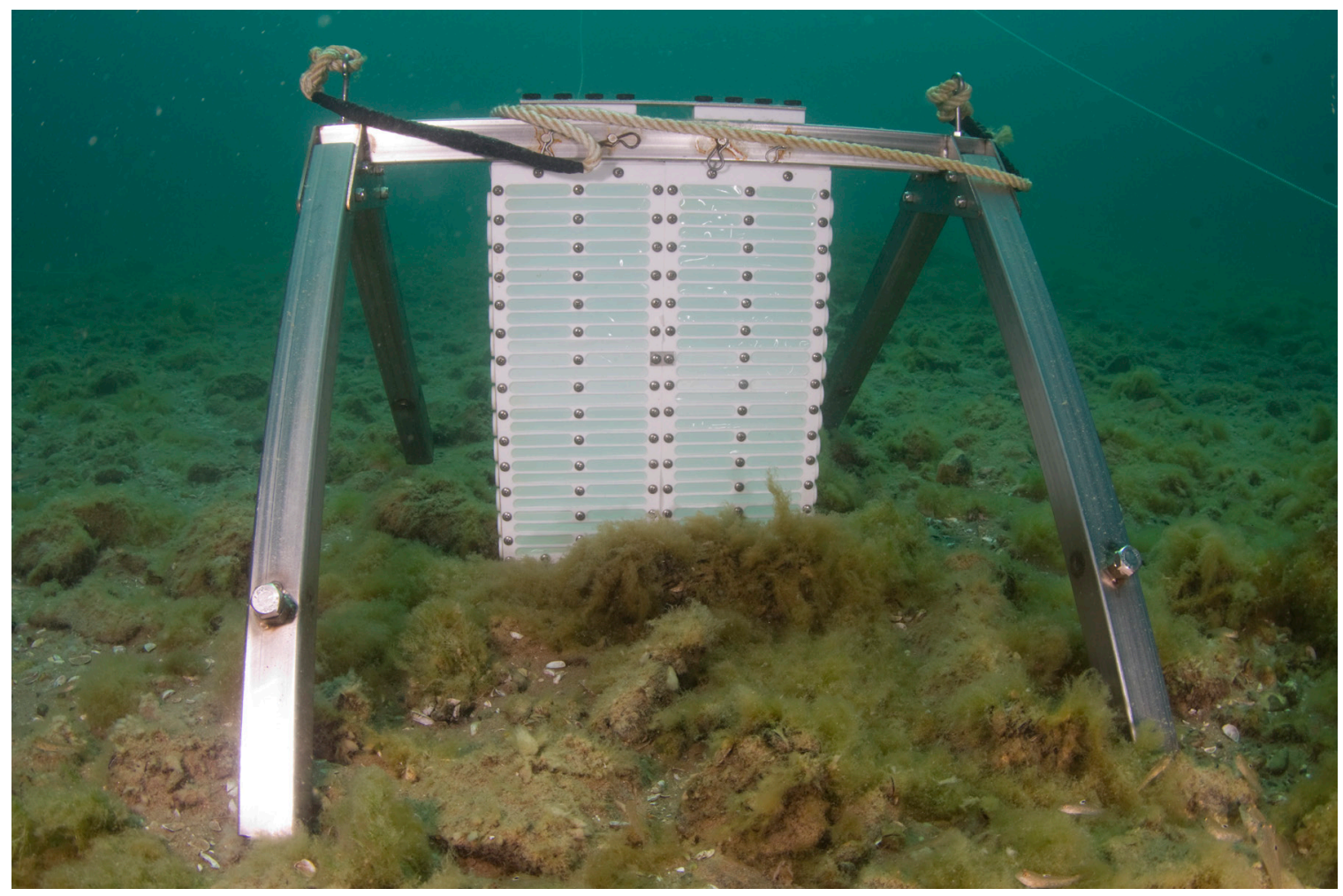

Figure 3.3: Modified Hesslein Sampler (peeper): Deployed over Cladophora and mussel bed. (Photo courtesy of: Chris Doyal). 


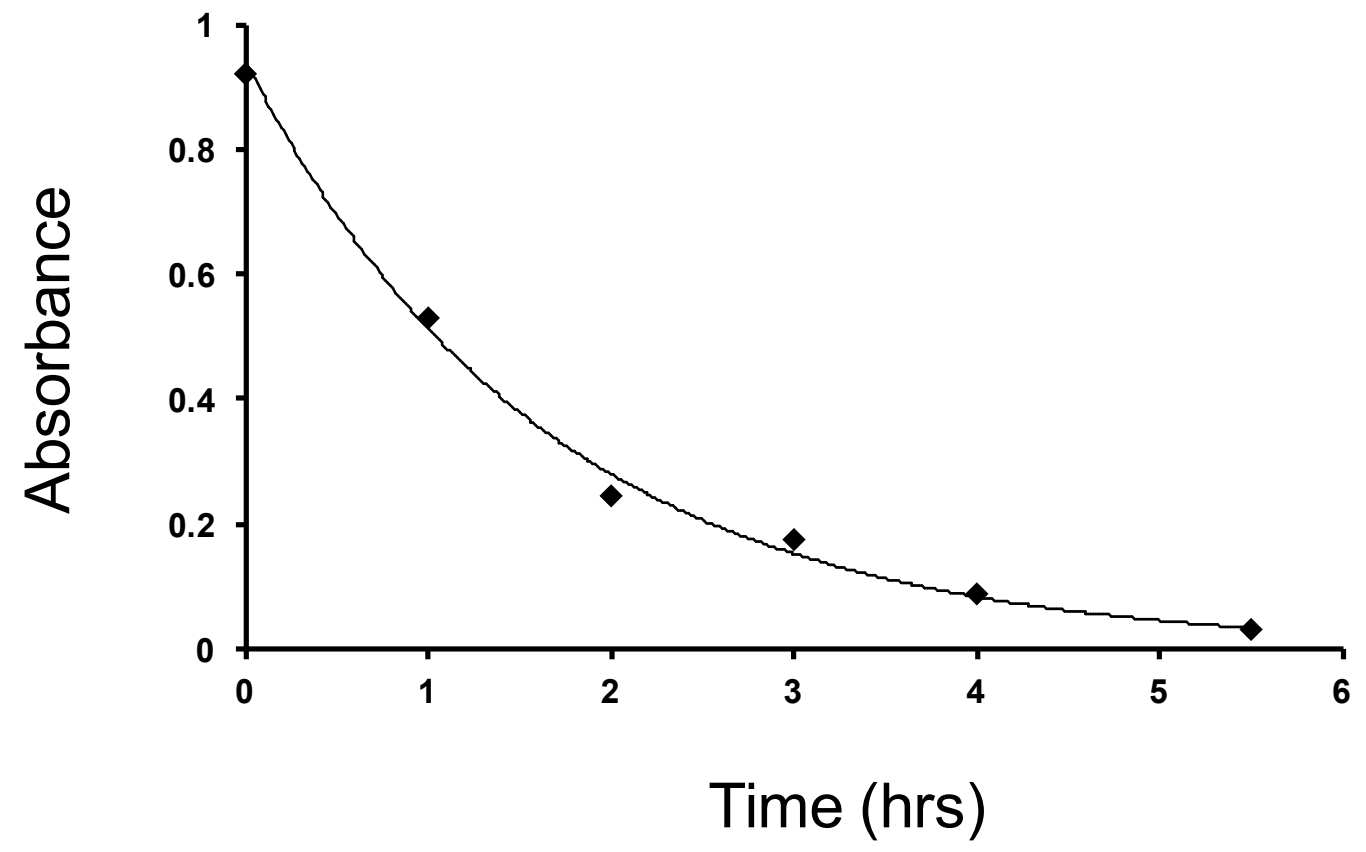

Figure 3.4: Equilibration of a peeper containing fluorescein dye following immersion in distilled water. The presence of the dye was measured as absorbance using a spectrophotometer. Equilibration time estimated to be $\sim 6$ hours, i.e. absorbance $\rightarrow 0$. 
At harvest, Teflon caps were removed from each cell and a glass syringe was used to transfer the sample to an acid-washed glass vial (Appendix A). Distilled water was used to rinse the syringe between samples. Samples were also collected at the surface, mid and bottom levels of the water column for determination of ambient soluble and particulate phosphorus concentrations. Samples were filtered at low pressure $(<100 \mathrm{~mm} \mathrm{Hg})$ using a vacuum pump and $0.45 \mu \mathrm{m}$ polycarbonate filters; the soluble fraction was maintained at $4^{\circ} \mathrm{C}$ until analysis, within 24 hours of collection, and the particulate fraction was frozen.

\subsection{Chemical Analysis}

Analysis of soluble phase samples was performed at the project laboratory in Frankfort, Ml according to the ascorbic acid method (Appendix B, Eaton 2005). Absorbance was measured at $880 \mathrm{~nm}$ on a Perkin Elmer UV/VIS Lambda 2 spectrometer using $10 \mathrm{~cm}$ glass cells. The detection limit for the method was

$0.46 \mu \mathrm{gP} \cdot \mathrm{L}^{-1}$ with excellent precision over the range $0-5 \mu \mathrm{gP} \cdot \mathrm{L}^{-1}\left(\mathrm{R}^{2}=0.9927\right.$; Figure 3.5). Particulate $P$ was determined by digestion and filtration of the sample followed by analysis using the aforementioned ascorbic acid method.

The method detection limit (MDL) and practical quantification limit (PQL) were determined by analyzing six replicate samples at each of four concentrations in the vicinity of the anticipated detection limit: $1 \mu \mathrm{gP} \cdot \mathrm{L}^{-1}, 2$ $\mu \mathrm{gP} \cdot \mathrm{L}^{-1}, 3 \mu \mathrm{gP} \cdot \mathrm{L}^{-1}$, and $4 \mu \mathrm{gP} \cdot \mathrm{L}^{-1}$ (Figure 3.6). The mean and standard deviation was then determined for each concentration and a one-sided tdistribution $(\alpha=0.05)$ established. The t-distribution was multiplied by the 


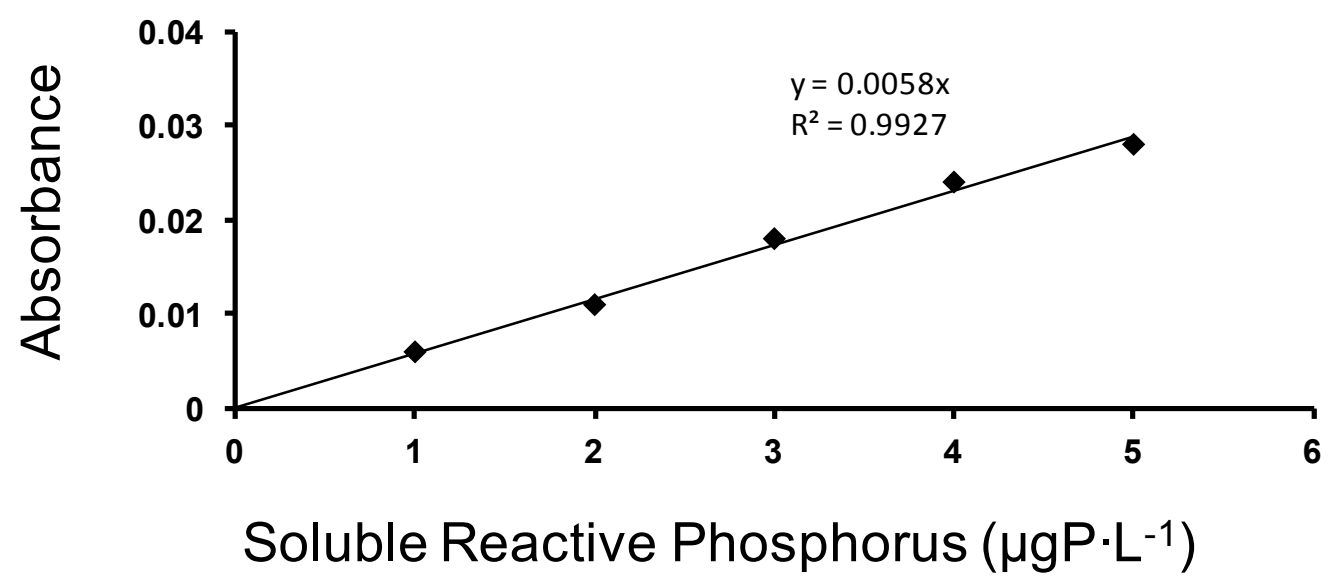

Figure 3.5: Standard curve for soluble reactive phosphorus. 


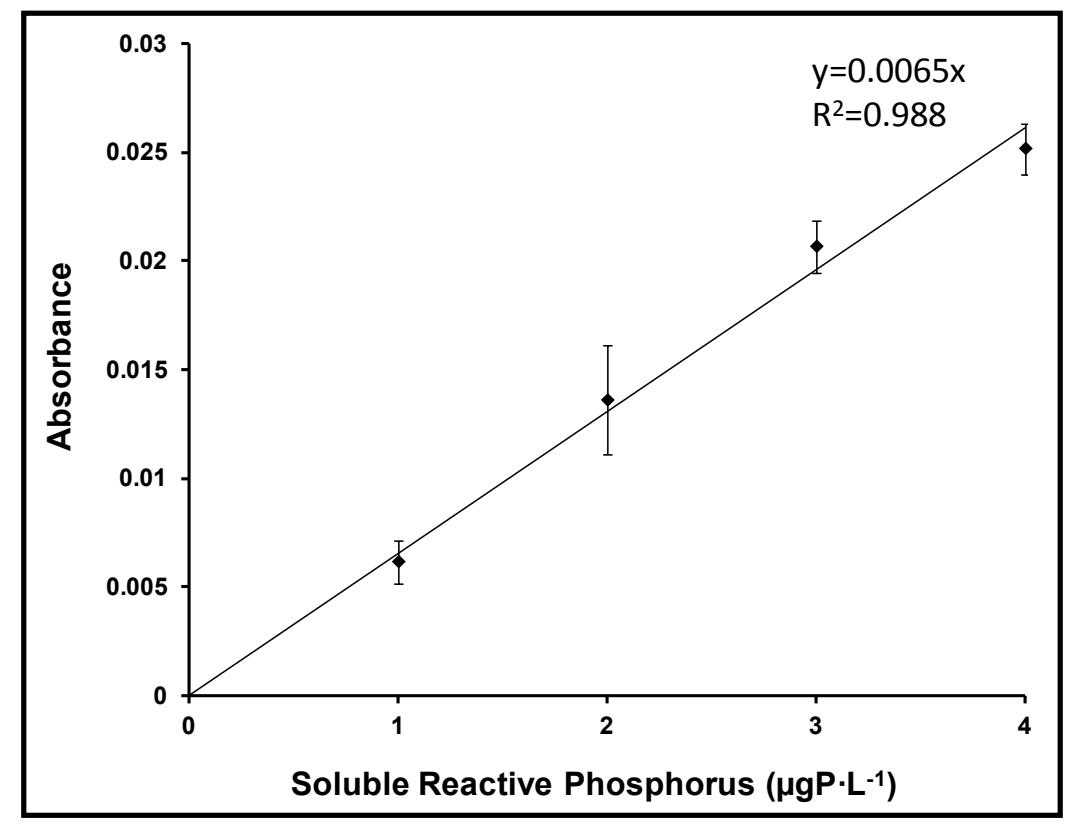

Figure 3.6: Standard curve for detection limit calculation.

Table 1

SRP, MDL and PQL

\begin{tabular}{|c|c|c|c|c|}
\hline$\underset{C}{\text { Nominal }}$ & $\begin{array}{l}\text { Std. Dev. } \\
\text { (ugP. } \mathrm{L}^{-1} \text { ) }\end{array}$ & $\mathbf{n}$ & $\begin{array}{l}95 \% \mathrm{MDL} \\
\text { (ugP. } \mathrm{L}^{-1} \text { ) }\end{array}$ & $\begin{array}{l}95 \% \mathrm{PQL} \\
\text { (ugP. } \mathrm{L}^{-1} \text { ) }\end{array}$ \\
\hline 1 & 0.15 & 6 & 0.30 & 1.52 \\
\hline 2 & 0.39 & 5 & 0.83 & 4.15 \\
\hline 3 & 0.19 & 6 & 0.38 & 1.88 \\
\hline \multirow[t]{2}{*}{4} & 0.18 & 6 & 0.36 & 1.81 \\
\hline & & Mean & 0.47 & 2.34 \\
\hline
\end{tabular}


standard deviation to obtain the $95 \% \mathrm{MDL}$ at each concentration, resulting in a mean $\mathrm{MDL}$ of $0.46 \mu \mathrm{gP} \cdot \mathrm{L}^{-1}$. The PQL $\left(2.34 \mu \mathrm{gP} \cdot \mathrm{L}^{-1}\right)$ was calculated by multiplying the MDL by five (Table 1 ).

\subsection{Hemisphere Study}

Phosphorus fluxes from mussels are a significant input to the mass balance for waters above their beds. A hemisphere study was conducted through which mass transport effects were minimized and near maximum (i.e. algal uptake was not accounted for) rates of phosphorus accumulation could be observed. Mussel phosphorus excretion was measured using an acrylic hemisphere (Figure 3.7; industrialplasticsonline.com) 18 inches in diameter with a $1 / 8$ inch thick wall. The hemisphere was modified by adding a bulb pipette on the side which was used to mix the contents and a rubber stopper at the top through which a tube was inserted for sample collection. The hemisphere was deployed over a representative bed of mussels and rocks were placed on the hemisphere flange to provide a tight seal and stabilize the deployment. Samples were collected at intervals over a 5-hour deployment using acid washed glass syringes. Hemisphere contents were gently mixed prior to collection using the bulb pipette.

\subsection{Meteorology and Mass Transport Profiling}

Wind speed was monitored at buoy and shore station locations (Figure 3.8) to support the development of correlations between turbulence and the nature of the concentration boundary layer (Figure 3.9). In addition, current 


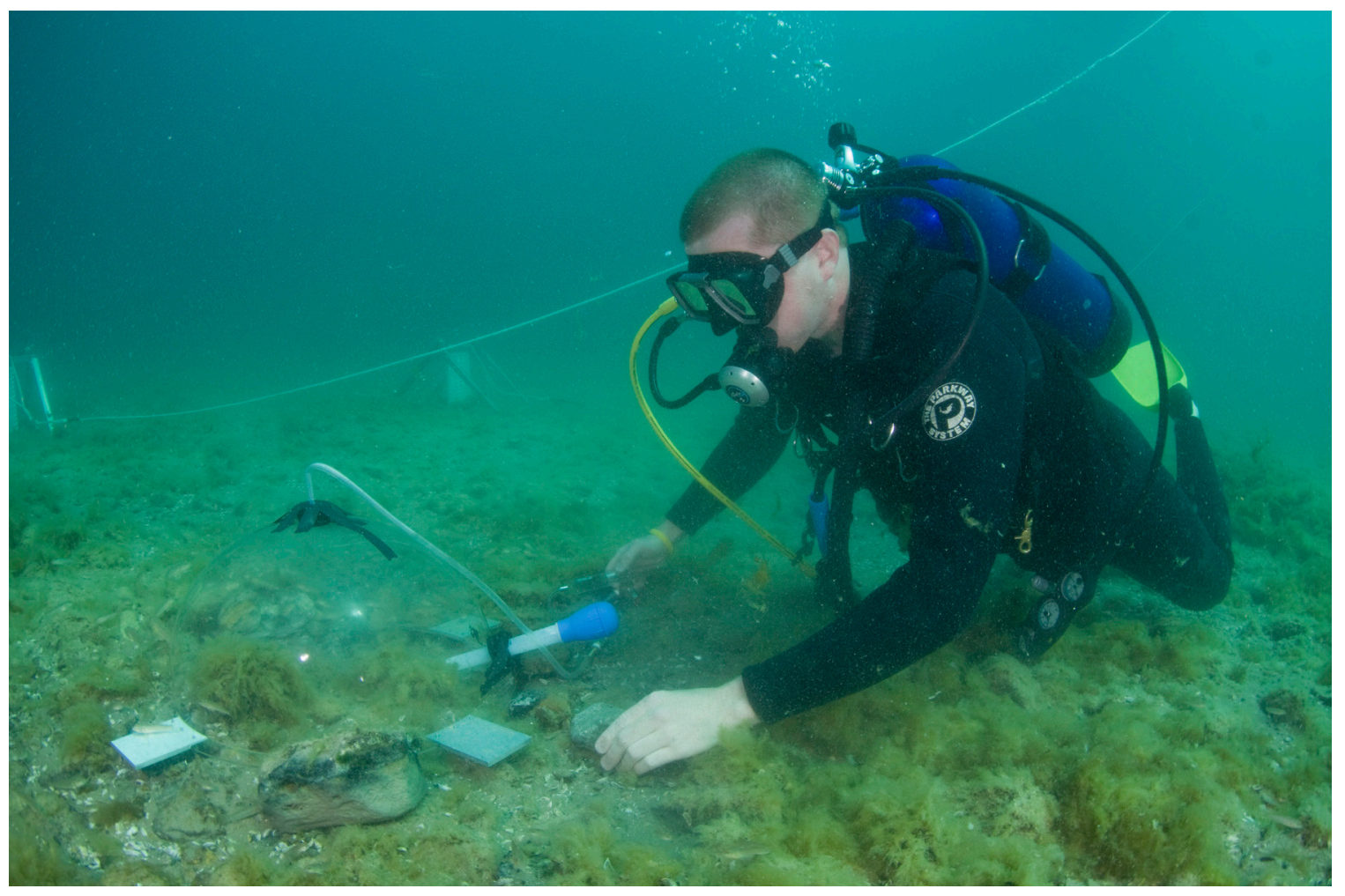

Figure 3.7: Diver situating dome for mussel P excretion potential study. 


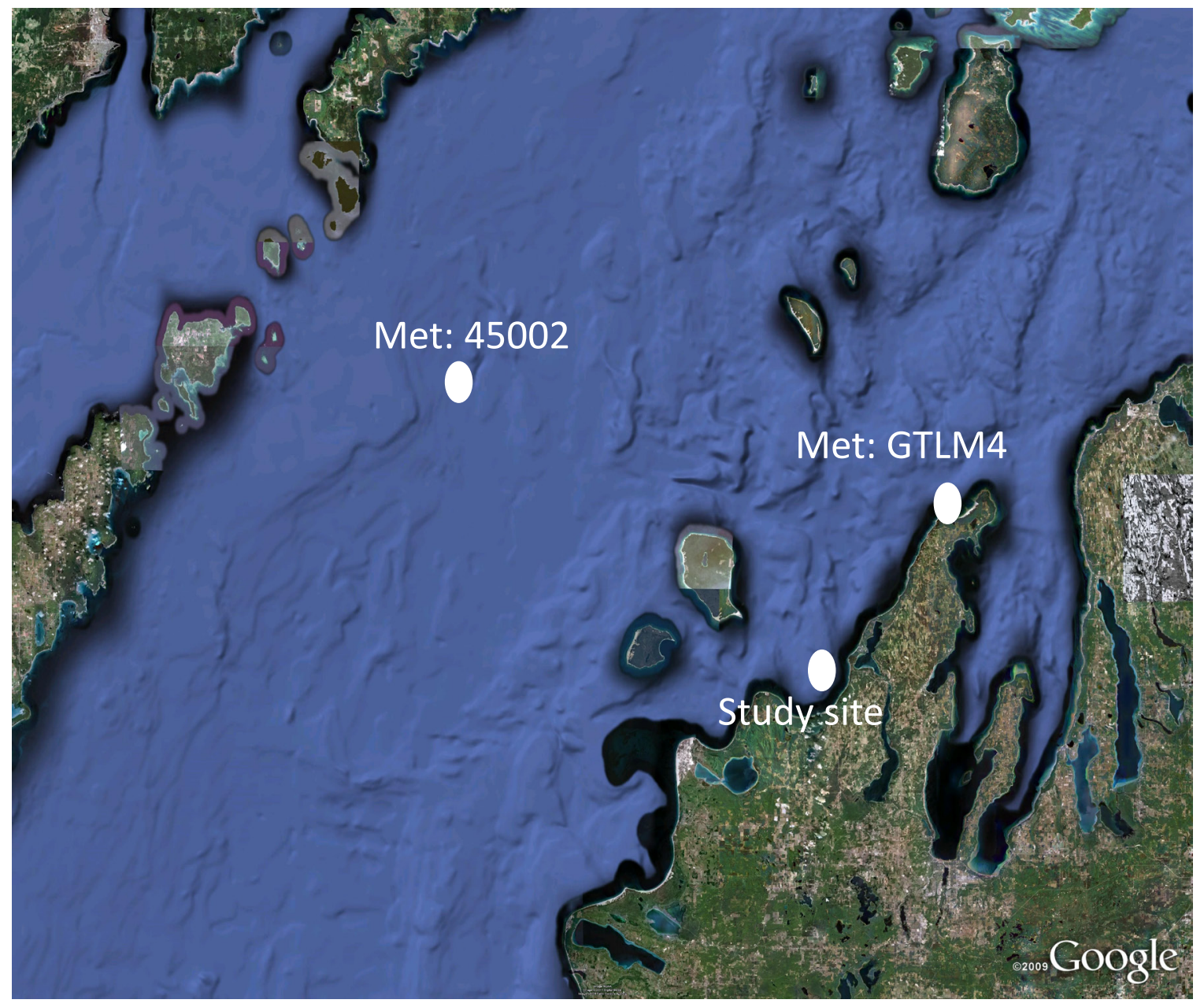

Figure 3.8: Met wind data buoys (NOAA; modified from Google earth). via NOAA Buoy GTLM4 at Grand Traverse Point and Station 45002 located on Lake Michigan between North Manitou Island and the Washington Islands. 


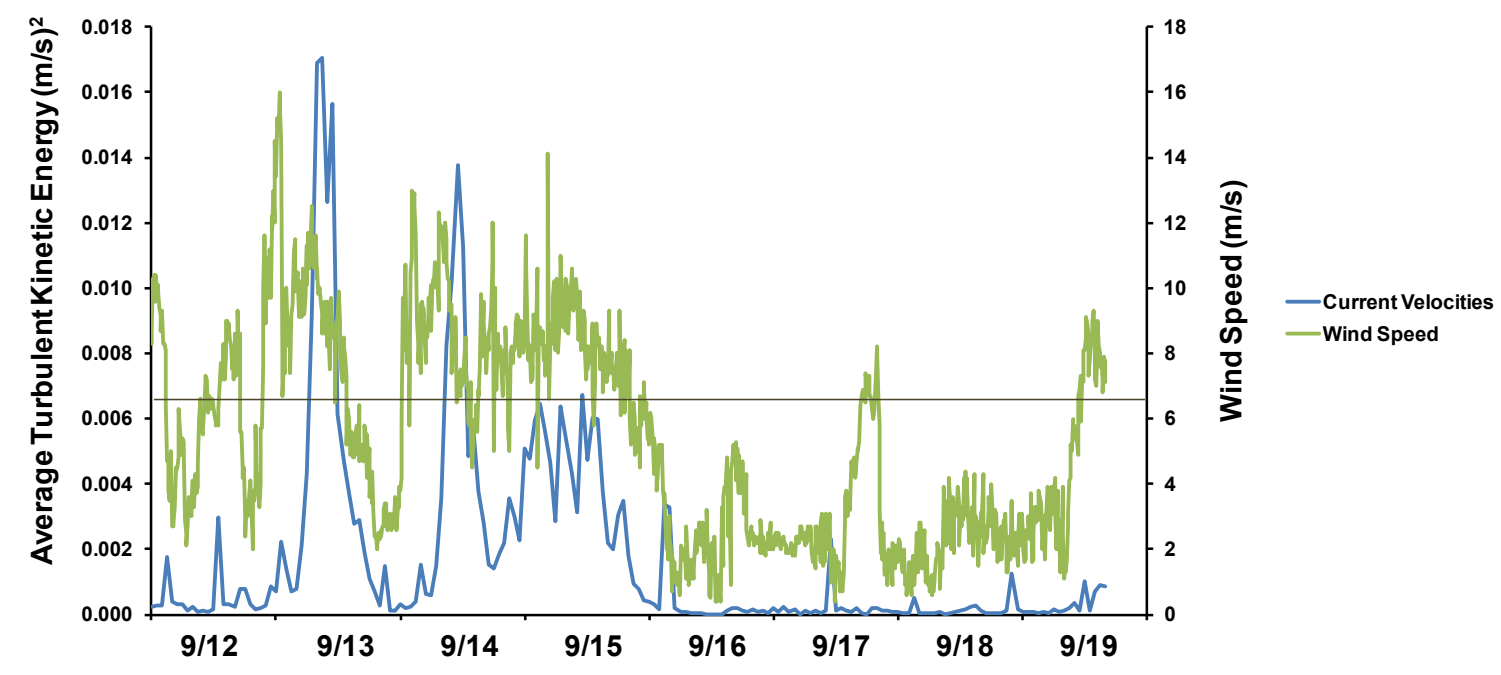

Figure 3.9: Wind speed and Current velocities from 9/12/11-9/19/11 with blue horizontal line illustrating the turbulent vs. quiescent wind regimes established by Boegman et al. 2008. 
velocity profiles were measured over the mussel beds using an Acoustic Doppler Current Profiler (ADCP; Nortek USA). The instrument was attached to a 3-meter tall stainless steel stand (Figure 3.10), configured to measure current velocities for a distance of 1.7 meters above the bed at $2 \mathrm{~cm}$ intervals and deployed in an 8-meter water column at the study site in Good Harbor Bay. Profiles were captured for a 5-minute duration at hourly intervals. Current data were used to calculate the turbulent diffusion coefficient as a function of distance over the bed and relate that turbulence to wind speed. ADCP measurements were not paired with peeper deployments. 


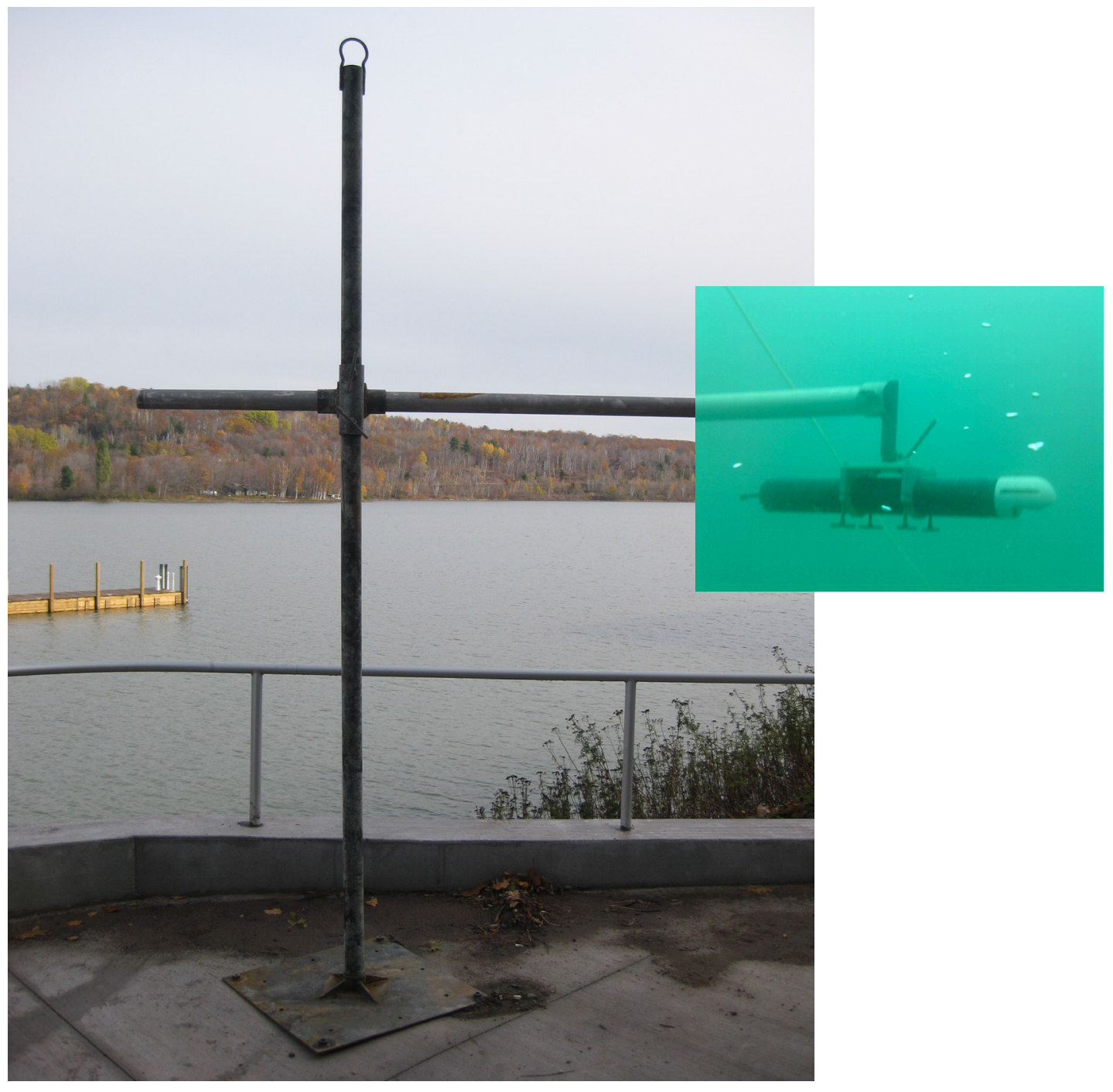

Figure 3.10: ADCP. 


\subsection{Results and Discussion}

The nearshore phosphorus shunt describes the process by which mussels capture particulate phosphorus and excrete it as soluble reactive phosphorus, the form available for uptake by Cladophora (Hecky et al. 2004). Ozersky et al. (2009) have demonstrated that the phosphorus flux from mussels can meet or exceed the stoichiometric requirement for Cladophora growth. However, phosphorus uptake by Cladophora is dependent on water column $\mathrm{P}$ levels as influenced by mass transport and only indirectly dependent on mussel fluxes. Therefore, a mechanistic link describing the impact of mass transport on water column $\mathrm{P}$ is required.

Before seeking to quantify this relationship, it is worthwhile to consider the range of SRP levels that are ecologically meaningful with respect to Cladophora growth. Ambient SRP levels in environments not supporting Cladophora growth, e.g. Lake Superior, suggest a lower limit for Cladophora growth of $\sim 0.5 \mu \mathrm{gP} \cdot \mathrm{L}^{-1}$ (Tomlinson et al. 2010). Tomlinson et al. (2010) have established that Cladophora becomes P-saturated at soluble reactive phosphorus concentrations greater than $\sim 1.5 \mu \mathrm{gP} \cdot \mathrm{L}^{-1}$ (Figure 4.1). Thus Cladophora growth may be considered to be most sensitive to SRP concentrations in the range, $0.5 \mu \mathrm{gP} \cdot \mathrm{L}^{-1}$ (limitation threshold) to $1.5 \mu \mathrm{gP} \cdot \mathrm{L}^{-1}$ (saturation threshold).

\subsection{Mussel phosphorus excretion potential}

Phosphorus fluxes from mussels are an integral component in the mass balance describes governance of water column concentrations. For the Lake 


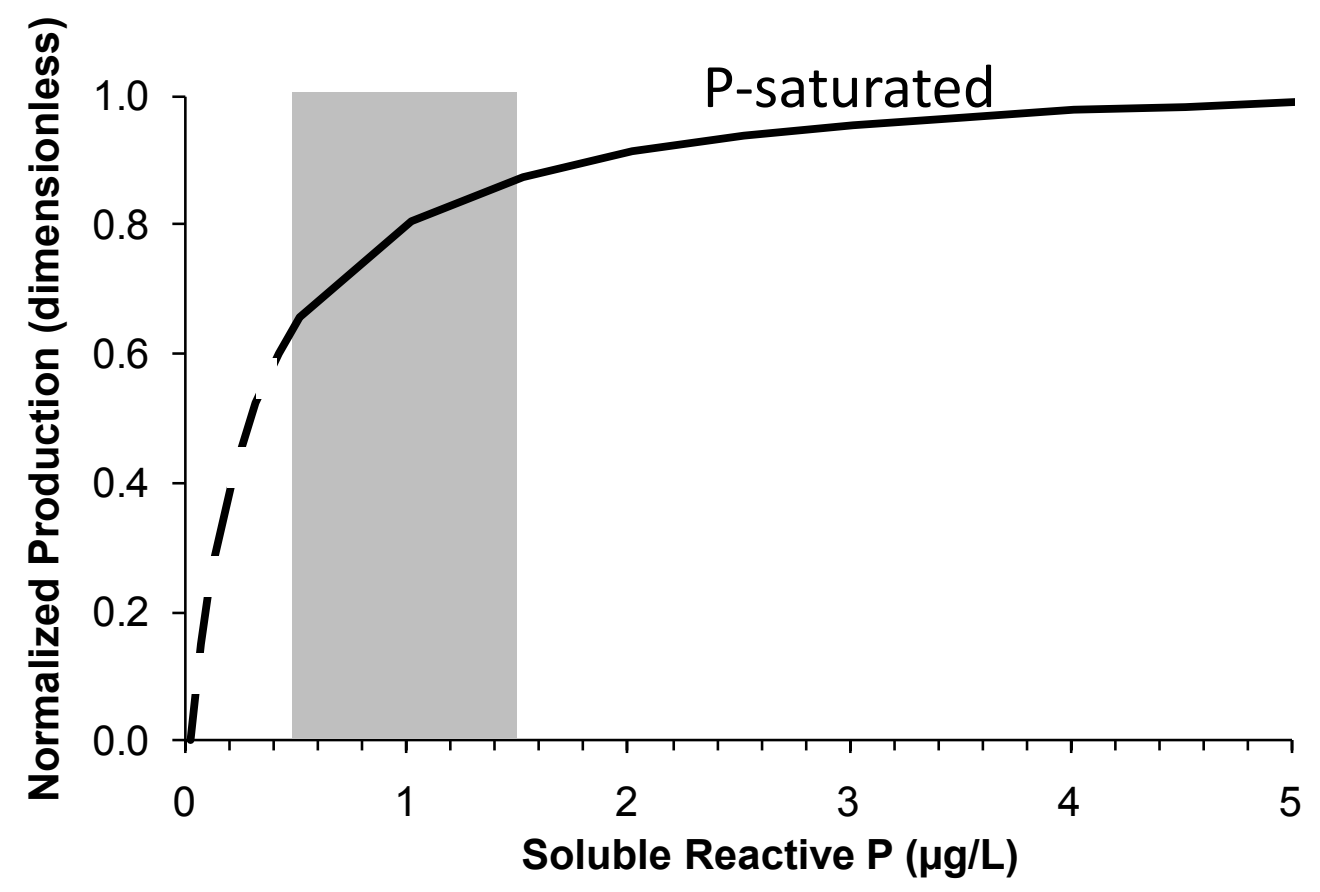

Figure 4.1: Production of Cladophora as a function of soluble reactive phosphorus concentration (modified from Tomlinson et al. 2010). The dashed line represents the SRP concentrations at which Cladophora is not at nuisance conditions and the P-saturated region is the area greater than $1.5 \mu \mathrm{gP} \cdot \mathrm{L}^{-1}$. 
Michigan study site, the average ambient water column SRP concentration of $0.47 \mu \mathrm{gP} \cdot \mathrm{L}^{-1}\left( \pm 0.13 \mu \mathrm{gP} \cdot \mathrm{L}^{-1} ;\right.$ Figure 4.2$)$ represents the case boundary condition, i.e. lake water uninfluenced by mussel excretion. This ambient SRP concentration is essentially identical to the lower end member of the range of ecologically meaningful SRP concentrations (Figure 4.1) and, thus, Cladophora growth at the study site is not driven by whole lake phosphorus levels.

An ambient SRP maximum (the magnitude of which would vary with the PP concentration and mussel population characteristics) would be observed in the presence of mussels but in the absence of mass transport and uptake by Cladophora. The maximum was characterized here by deploying a dome over a mussel/Cladophora bed at the high density site and measuring the concentration of SRP over time (Figure 4.3). The results of this study are best examined in terms of a mass balance on $\mathrm{P}$ in the hemisphere. Initially, PP and SRP were at levels reflecting the ambient near-bottom environment (high and low, respectively), concentrations favoring mussel excretion over Cladophora uptake and yielding a steep positive slope in observed SRP concentration (Figure 4.3, 'a'). After $\sim 30$ minutes incubation, PP would have decreased resulting in less excretion, while SRP was observed to increase, leading to more rapid uptake (Auer et al., 1982). Conditions continued to favor excretion, but the slope was less (Figure 4.3, 'b'). After 2 hours, PP was likely depleted and mussel excretion negligible; Cladophora uptake drove down SRP and the result was a descending slope (Figure 4.3, 'c'). As PP and SRP were both drawn down, a steady state 


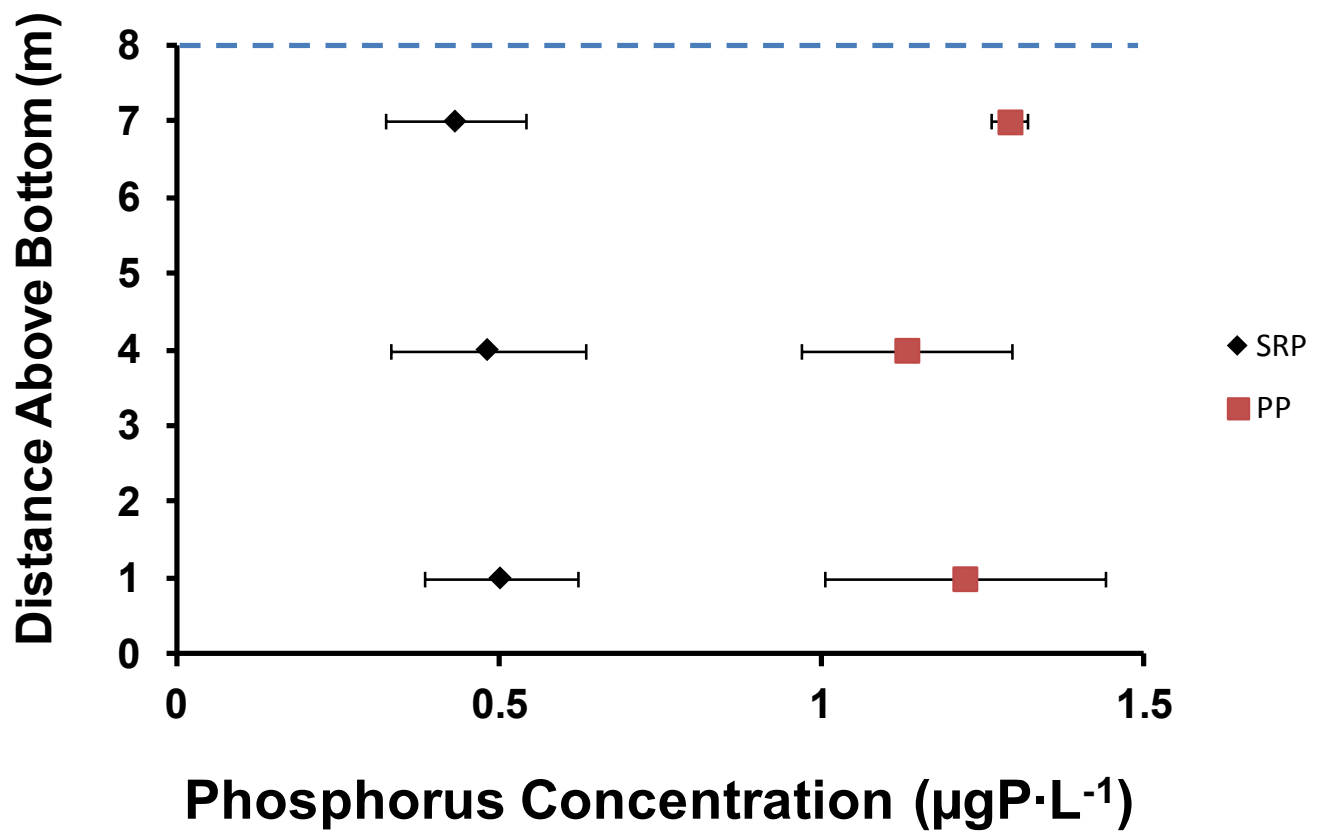

Figure 4.2: Water column (boundary condition) soluble reactive phosphorus concentrations at $1 \mathrm{~m}$ below the surface, mid-depth $(4 \mathrm{~m})$ and $1 \mathrm{~m}$ above the lake bottom. Results are presented as mean \pm S.D. for 9 measurements of the MayOct period of 2011. 


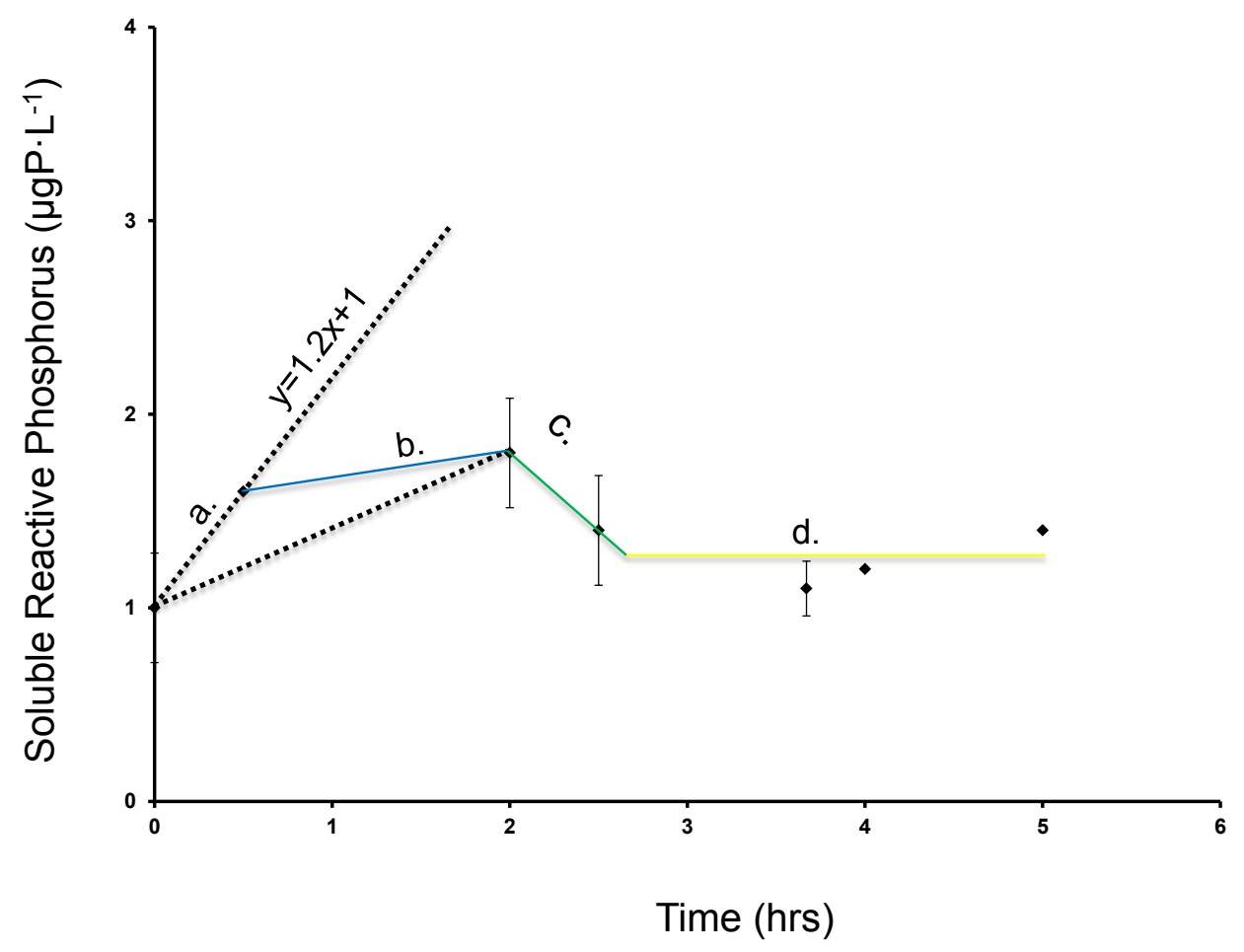

Figure 4.3: Soluble Reactive Phosphorus Concentrations over mussels surrounded by dome. 
was achieved (zero slope; (Figure 4.3, 'd'). The initial positive slope (1.2 $\left.\mu \mathrm{gSRP} \cdot \mathrm{L}^{-1} \cdot \mathrm{hr}^{-1}\right)$ yields an SRP mussel excretion flux of $4.4 \mathrm{mgSRP} \cdot \mathrm{m}^{2} \cdot \mathrm{d}^{-1}$ (Appendix C; mussel density of $4000 \mathrm{~m}^{-2}$.) Corrected for Cladophora uptake, this excretion rate would be higher. This excretion rate falls between that calculated from field measurements made by Ozersky et al. $2009\left(3 \mathrm{mgSRP} \cdot \mathrm{m}^{2} \cdot \mathrm{d}^{-1}\right)$ and rates calculated using an empirical algorithm $\left(6.5 \mathrm{mgSRP} \cdot \mathrm{m}^{2} \cdot \mathrm{d}^{-1}\right.$ Bootsma, unpublished). While the mussel SRP flux can only be sustained if the supply of particulate $P$ is maintained, fluxes of the magnitude determined here could elevate ambient near-bottom SRP concentrations to $2-5 \mu \mathrm{gP} \cdot \mathrm{L}^{-1}$ over periods of 2-4 hours. Thus, absent mass transport and uptake by Cladophora, mussels can generate ecologically significant SRP concentrations. The impact of Cladophora uptake can be dismissed as the significance of this loss term will decline as stored $\mathrm{P}$ is accumulated, a phenomenon which proceeds at a time scale much shorter than that of excretion (Auer et al. 1982).

Mass transport serves to mediate both the rate of PP supply to mussels and the rate of SRP removal from the boundary layer. A low degree of diffusive mass transport tends to enhance accumulation, but limit supply through excretion. Thus, this phenomenon is complex and this is why modeling is necessary.

\subsection{Observations}

A broad range in the character of near-bottom SRP profiles was observed (Figure 4.4). Profiles varied with respect to boundary layer thickness (e.g. compare Figure $4.4 \mathrm{f}$ with Figure $4.4 \mathrm{I}$ ) as well as maximum boundary layer SRP 

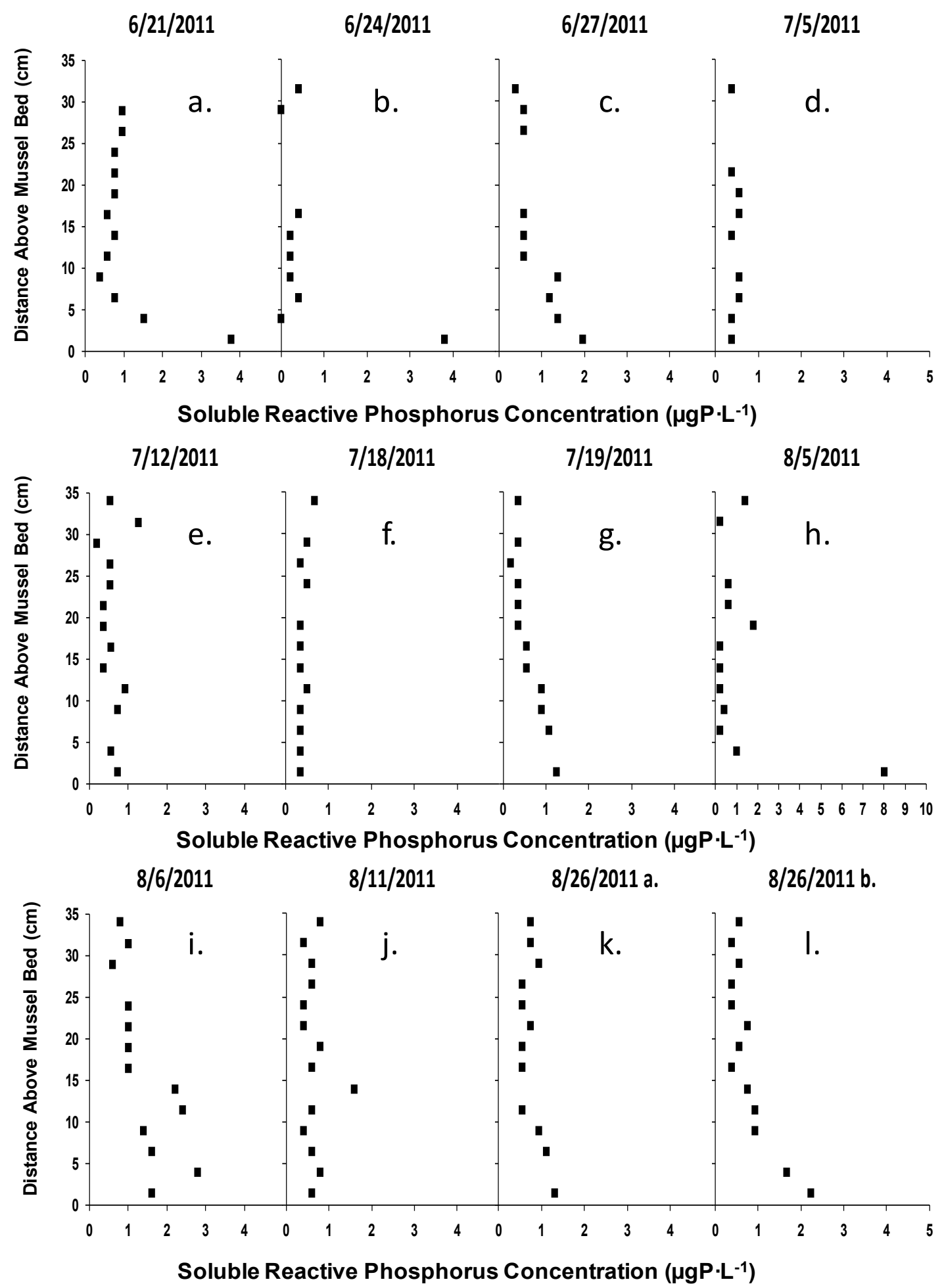

Figure 4.4: Peeper profiles of SRP concentrations collected June-August, 2011. 
concentration (compare Figure 4.4a vs. $4.4 \mathrm{~h}$ ). These differences in boundary layer thickness and concentration gradients are attributable to factors including the magnitudes of mass transport and mussel density. During quiescent periods, an SRP concentration boundary layer builds up above the mussel bed while turbulent conditions serve to entrain the boundary layer resulting in more uniform SRP distributions. Here, the impact of three driving forces will be considered: mussel density (4.2.1) and two features of mass transport (wind speed, Figure 4.2.2, and the duration of quiescent conditions Figure 4.2.3).

\subsubsection{The impact of mussel density on boundary layer concentrations}

Mussel P fluxes vary with respect to PP supply, temperature, mussel size and density (Bootsma unpublished). Holding the first three factors constant, increasing mussel density should result in greater fluxes. For a given mixing condition, higher fluxes have the potential to yield greater phosphorus concentrations in the boundary layer above the mussel beds (Figure 4.5a). Observations support the conceptual model as evidenced by the fact that maximum near-bottom SRP concentrations for the high density bed $\left(8 \mu \mathrm{gP} \cdot \mathrm{L}^{-1}\right)$ were greater than those observed over the lower density bed $\left(4 \mu \mathrm{gP} \cdot \mathrm{L}^{-1}\right.$; Figure 4.5b). Wind speeds (used here as a surrogate for mass transport) were similar for the two, remaining below the $6 \mathrm{~m} \cdot \mathrm{sec}^{-1}$ threshold of Boegman et al. (2008) for $\geq 24$ hours prior to harvest. These observations support the hypothesis that a phosphorus boundary layer, $5-15 \mathrm{~cm}$ in thickness, forms within and immediately above habitat colonized by dreissenids and Cladophora under appropriate mixing 


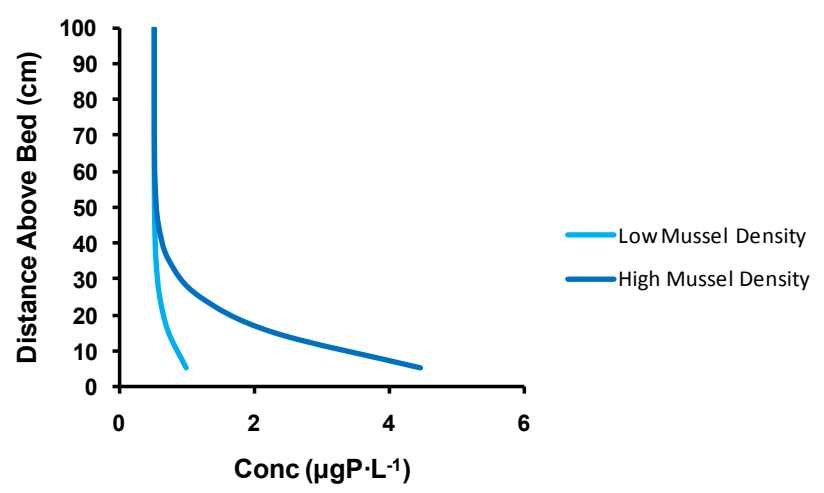

Figure 4.5a: Conceptualization of phosphorus profiles reflecting the impact of mussel density on concentrations in the boundary layer.
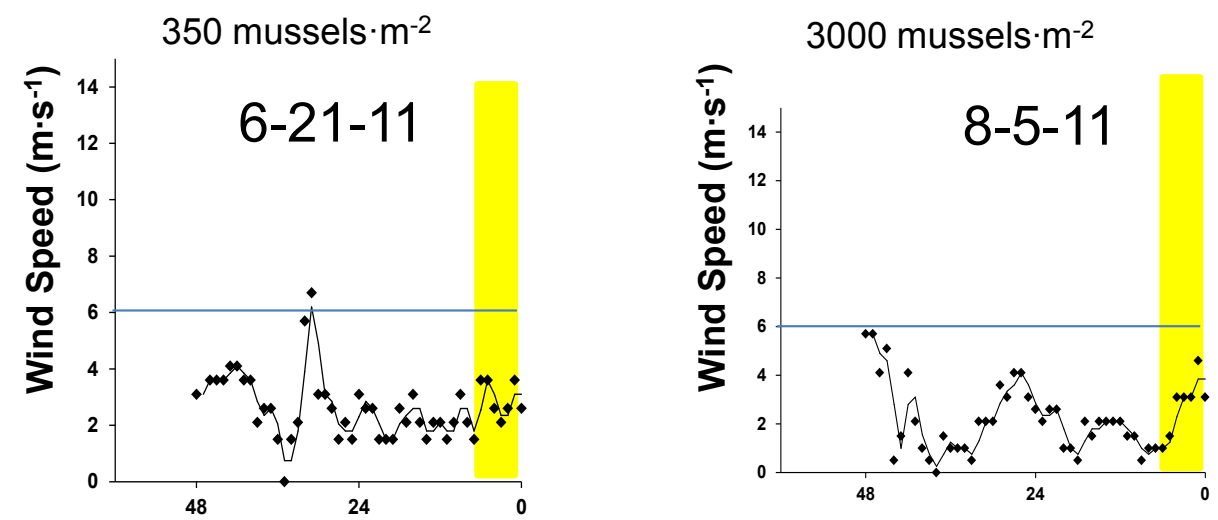

Time Prior to Harvest (hr)
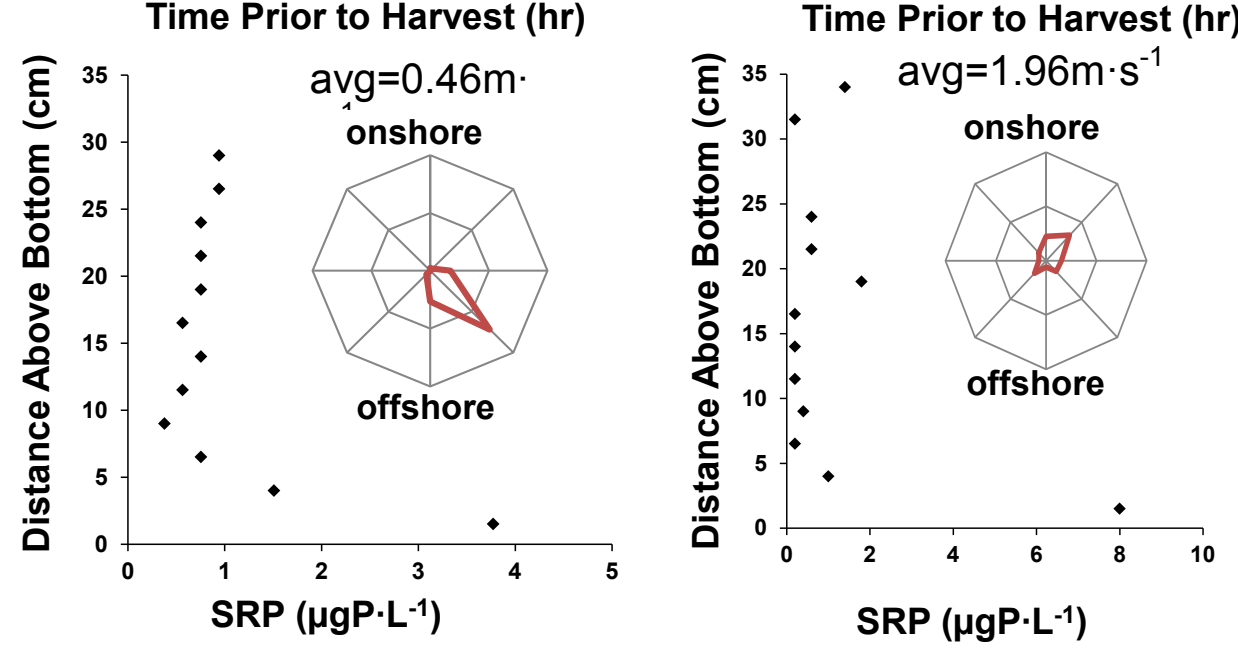

Figure 4.5b: Observed phosphorus profiles confirming the conceptual model for the impact of mussel density on phosphorus concentrations in the boundary layer. 
conditions and that the magnitude of concentration within the boundary layer varies with mussel density.

\subsubsection{The impact of wind speed on boundary layer concentrations}

Wind is the predominant driving force for mass transport in the nearshore waters inhabited by Cladophora. As wind speeds increase, higher rates of diffusion are observed, eventually leading to entrainment of the concentration boundary layer (Figure 4.6a). Profiles associated with winds of increasing speed $\left(2.1,3.8\right.$, and $\left.6.9 \mathrm{~m} \cdot \mathrm{s}^{-1}\right)$ support the conceptual model, i.e. entrainment is observed to increase concomitantly maximum SRP concentrations decreasing from $3.8 \mu \mathrm{gP} \cdot \mathrm{L}^{-1}$ to $0.8 \mu \mathrm{gP} \cdot \mathrm{L}^{-1}$ (Figure $4.6 \mathrm{~b}$ ). These measurements support the concept introduced above that increasing wind speeds lead to decreasing boundary layer thickness and decreasing maximum near bottom concentrations.

\subsubsection{Impact of quiescent periods on boundary layer concentrations}

As described above, wind speeds of $<6 \mathrm{~m} \cdot \mathrm{s}^{-1}$, result in minimal mixing (Boegman et al. 2006) of an 8-meter water column, permitting development of a of a concentration boundary layer. Turbulent conditions, wind speeds of $\geq 6 \mathrm{~m} \cdot \mathrm{s}^{-}$ ${ }^{1}$, lead to destruction of that layer. The conceptual model suggests that the SRP gradient within the boundary layer increases with the duration of quiescent conditions (Figure 4.7a). Observations supported the conceptual model, with increases in the duration of quiescent conditions resulting in larger concentration gradients (Figure 4.7b). As quiescent period duration increased from 2 hours to48 hours the respective maximum SRP concentration increased from 0.6 


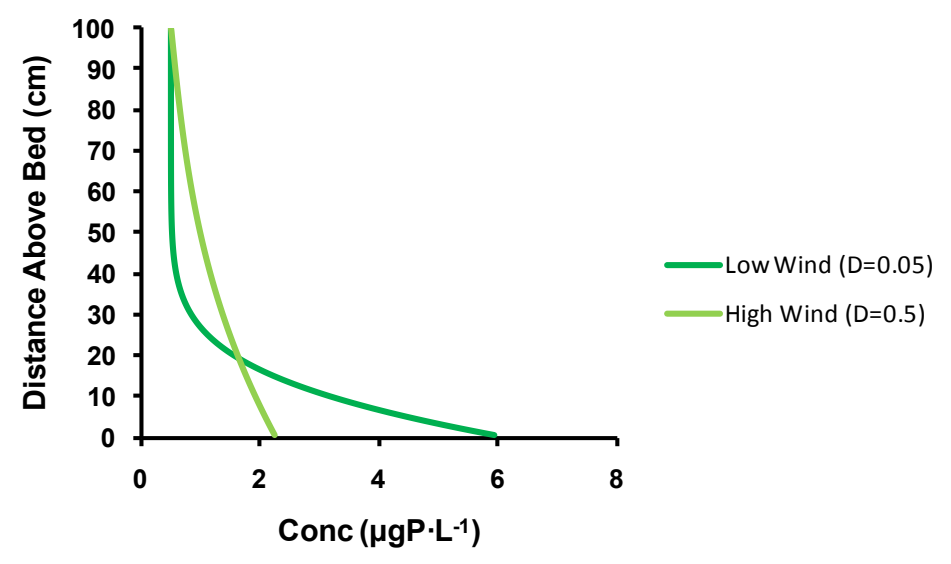

Figure 4.6a: Model-predicted phosphorus profiles illustrating the impact of wind speed on phosphorus concentrations in the boundary layer.

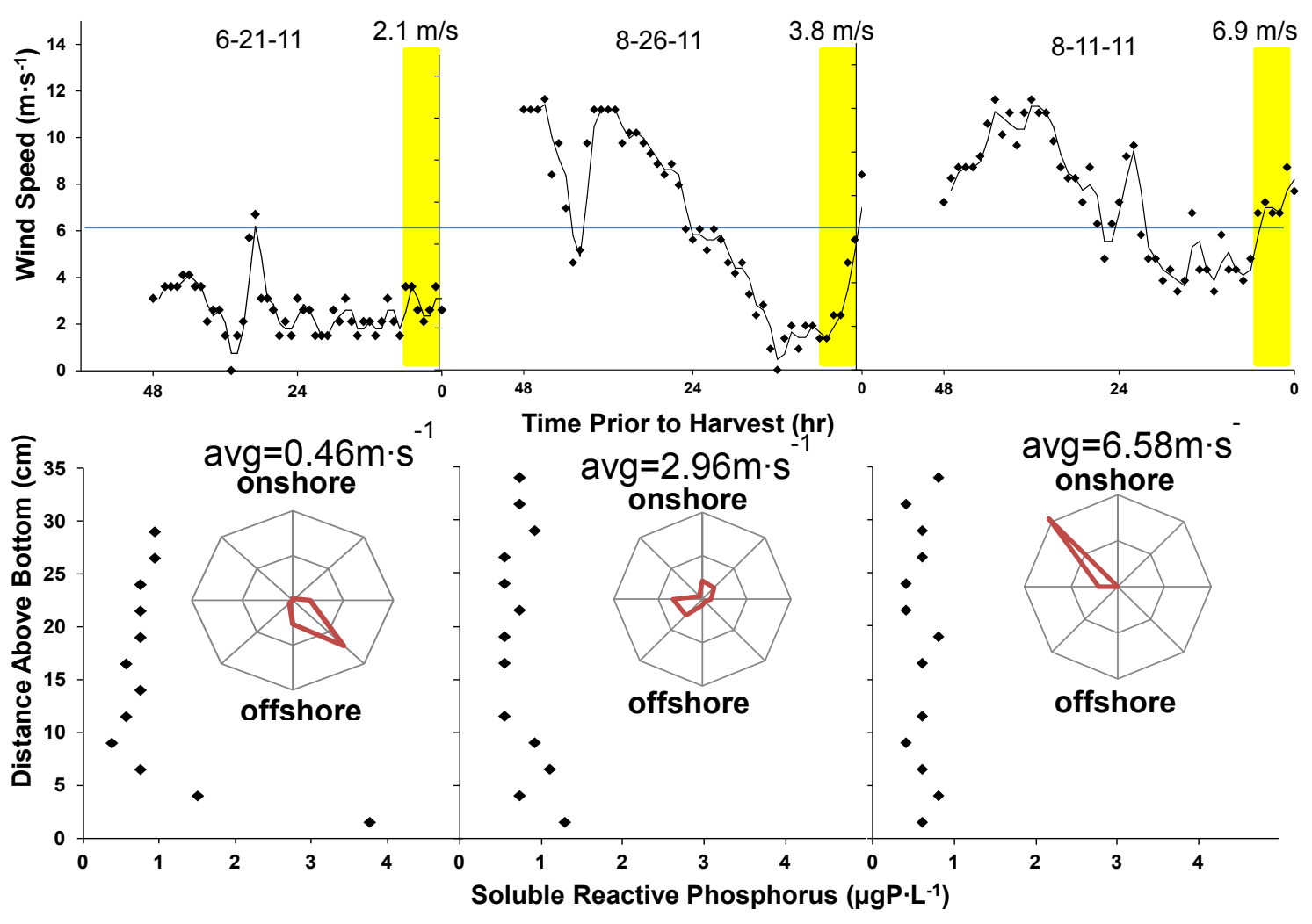

Figure 4.6b: Observed phosphorus profiles confirming the conceptual model for the impact of wind speed on phosphorus concentrations in the boundary layer. 


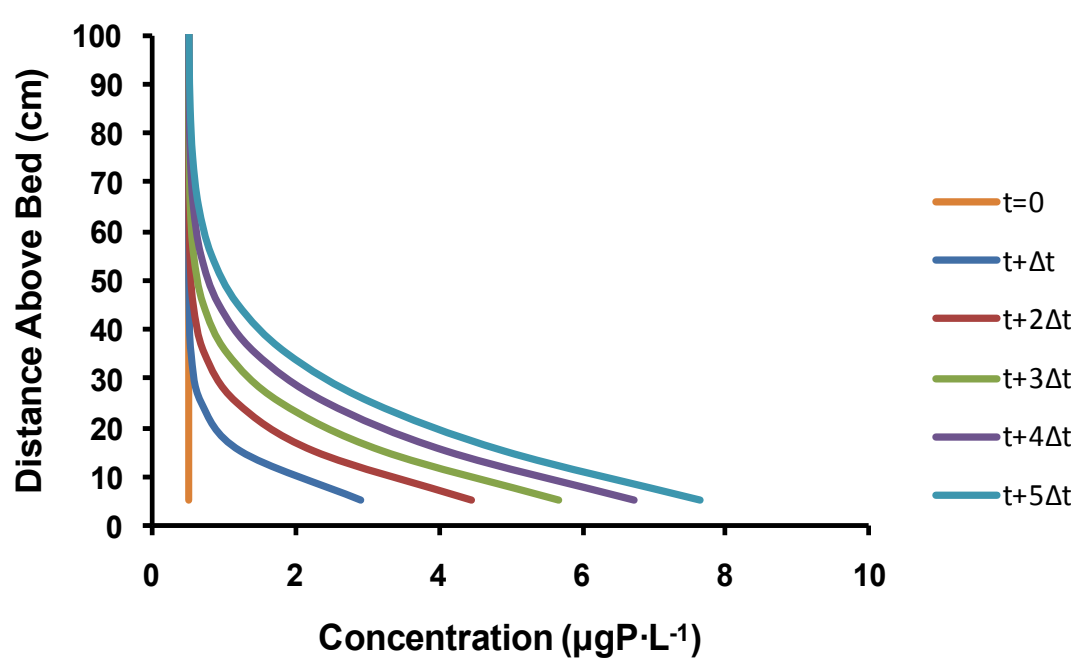

Figure 4.7a: Model-predicted phosphorus profiles illustrating the effect of quiescent periods on phosphorus concentrations in the boundary layer.
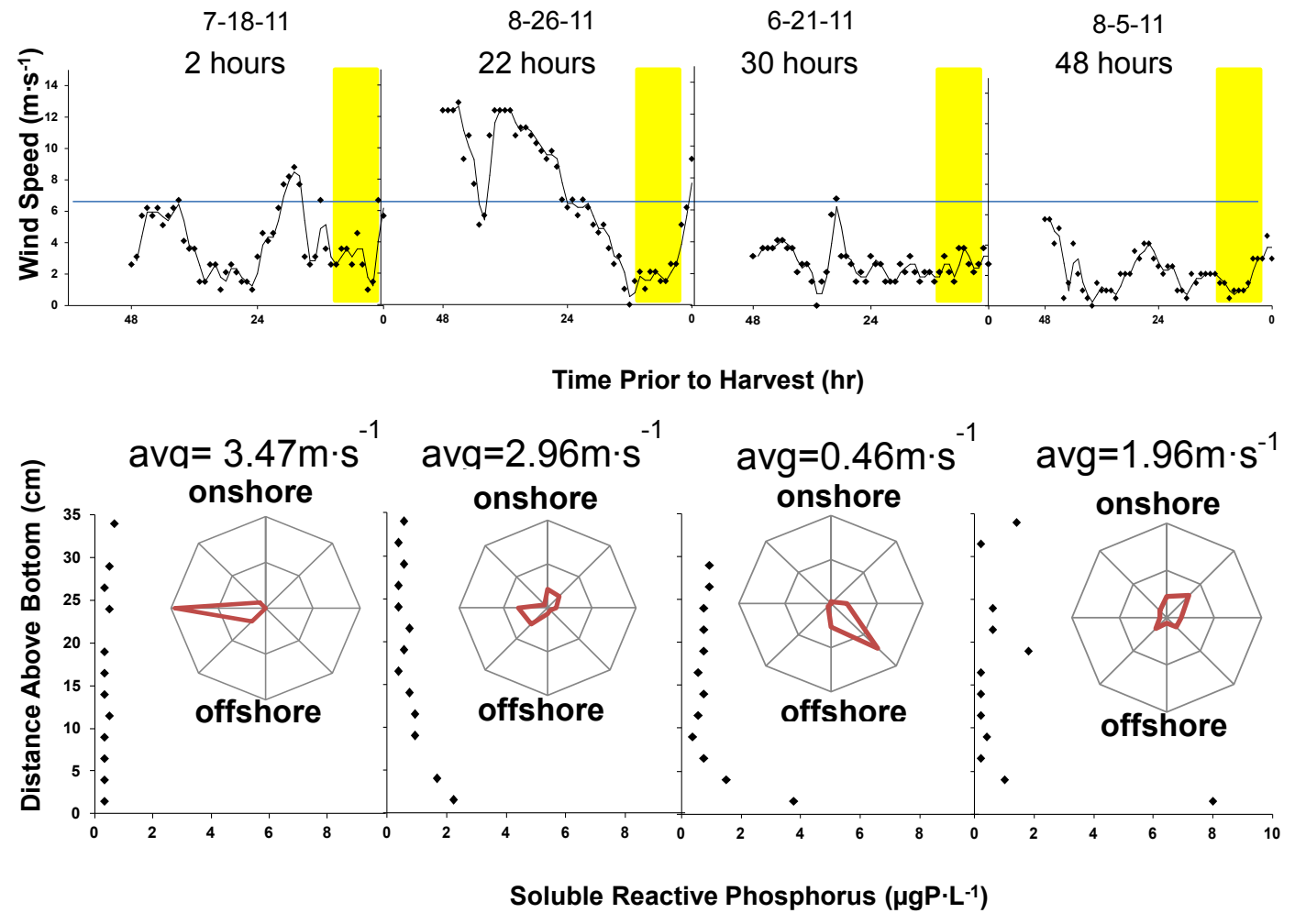

Figure 4.7b: Observed phosphorus profiles confirming the conceptual model for the impact of quiescent period duration on phosphorus concentrations in the boundary layer. (It should be noted that high wind speed at the last data point before harvest for 8-26-11 was taken $\sim 10$ minutes prior to harvest, thus not affecting profile given peeper's equilibration time of 5-6 hours.) 
$\mu \mathrm{gP} \cdot \mathrm{L}^{-1}$ to $8 \mu \mathrm{gP} \cdot \mathrm{L}^{-1}$ (with ambient water column boundary conditions unchanged). These observations support the hypothesis that the nature of the Phosphorus boundary layer that forms proximate to habitat colonized by dreissenids and Cladophora depends on the duration of quiescent conditions.

Prolific recyclers, mussels have the capacity to excrete a significant amount of SRP into the water column. During quiescent periods this flux can lead to an ecologically-meaningful increase in SRP concentrations in near-bottom waters. Turbulent conditions entrain the concentration boundary layer restoring the water column profile to that of the ambient open water environment unimpacted by mussels. The thickness of the concentration boundary layer that forms under quiescent conditions and the $\mathrm{P}$ levels contained therein varied with: mussel density, wind speed, and duration of quiescent conditions. The amount of phosphorus that was observed to accumulate in the concentration boundary layer is ecologically significant for Cladophora and occurs at a location in the water column inhabited by the algae $(\sim 0-10 \mathrm{~cm}$ above the mussel bed).

\subsection{Relating boundary layer profiles to meteorological conditions}

\subsubsection{Model}

A model is developed to simulate the one-dimensional (vertical) distribution of soluble reactive phosphorus $(P)$ in the water column overlying zebra mussel beds. The physical framework includes $800,1-\mathrm{cm}$ thick model cells representing a distance of $8 \mathrm{~m}$ above bottom, i.e. the deployment depth for 
peeper samplers. The basic governing equation is the one-dimensional diffusion equation,

$$
\frac{\partial P}{\partial t}=\frac{\partial}{\partial z}\left(D(z) \frac{\partial P}{\partial z}\right)
$$

where: $\mathrm{P}$ is the soluble reactive phosphorus concentration $\left(\mathrm{mgP} \cdot \mathrm{m}^{-3}\right), \mathrm{t}$ is time (d), $z$ is the vertical coordinate ( $\mathrm{m}$; positive upwards), and $D$ is the diffusion coefficient (length ${ }^{2} /$ time). The upper boundary condition is a fixed $\mathrm{P}$, which in general could be a function of time. The value is determined from direct measurement and user-input. The bottom boundary condition is a specified flux, determined from model calibration. Mathematically, this condition is expressed by

$$
J=-\left.\left(D(z) \frac{\partial P}{\partial z}\right)\right|_{z=0}
$$

where $\mathrm{J}$ is the mussel $\mathrm{P}$ flux $\left(\mathrm{gP} \cdot \mathrm{m}^{-2} \cdot \mathrm{d}^{-1}\right)$. The numerical solution is formulated using an explicit finite difference scheme with a simple forward difference in time and a central difference in $z$ for the diffusion term. It is solved with VBA in Excel.

\subsubsection{Fitting}

There are three features which characterize the phosphorus profile: the ambient bulk liquid boundary condition, the maximum SRP value at the sediment-water interface and the shape of the curve connecting those two. The boundary condition, averaging $0.47 \pm 0.13 \mu \mathrm{gP} \cdot \mathrm{L}^{-1}$ over the study (Figure 4.2), was measured and input in fitting each curve. The maximum SRP varies with the P flux from the mussel bed which is a function of mussel density and particulate 
$\mathrm{P}$ concentration. Under low mixing conditions, particulate $\mathrm{P}$ is depleted near the sediment-water interface (Boegman et al. 2008) and the flux decreases markedly over time, i.e. duration of quiescence. In calibrating the model, values of $\mathrm{J}$ and $\mathrm{D}$ were varied, seeking a best fit between measured and model-predicted $P$ values over the profile. This two-parameter calibration is expected to yield unique values for $\mathrm{J}$ and $\mathrm{D}$ as these coefficients mediate different portions of the profile (shape). A suitable fit was achieved in all 12 cases, including low and high mussel densities and low and high turbulence conditions (Figures 4.8-4.10).

\subsubsection{Flux and Duration of Quiescent Conditions}

Over the period of deployment the particulate phosphorus concentration decreases if mixing conditions are limited which leads to a reduction in SRP flux. The reduction becomes more significant as time of quiescence increases. Calibration supported this phenomenon as $\mathrm{J}$ had to be varied over time for both low and high mussel densities. A plot of $\mathrm{J}$ calibration as a function of quiescent period duration yields a strong correlation (Figure 4.12) and validates the decision to vary $\mathrm{J}$ in calibration to accommodate this decreasing PP concentration.

\subsubsection{Relation to wind speed}

The conceptual model guiding this research suggests that variations in wind speed would impact the magnitude of diffusion and thus the nature of the profile. While it is $\mathrm{J}$ that determines the near bottom concentration, it is diffusion and, indirectly wind, that establish the thickness of the boundary layer and thus 


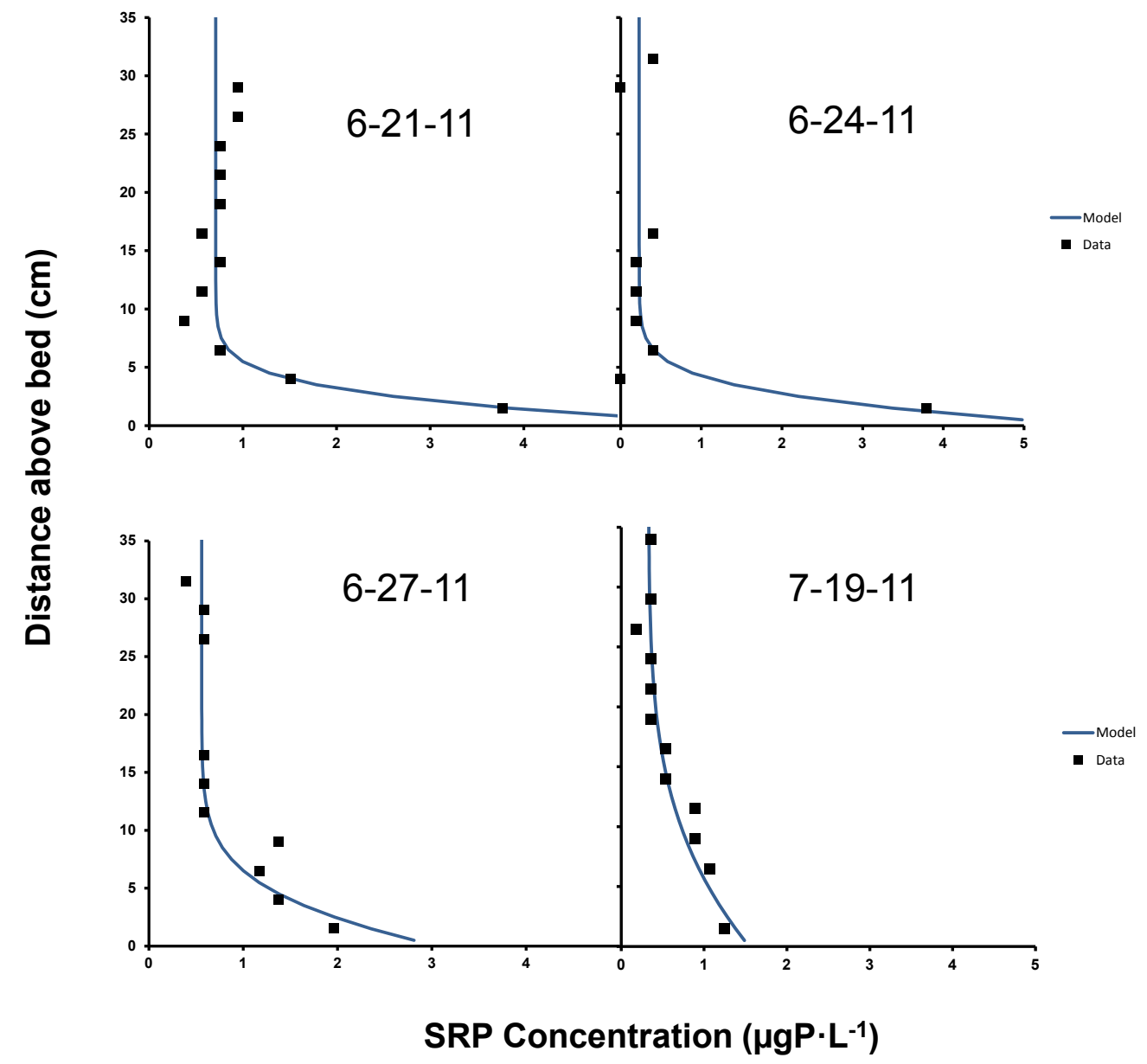

Figure 4.8: Peeper profiles calibrated to data for quiescent conditions at low mussel density locations. 


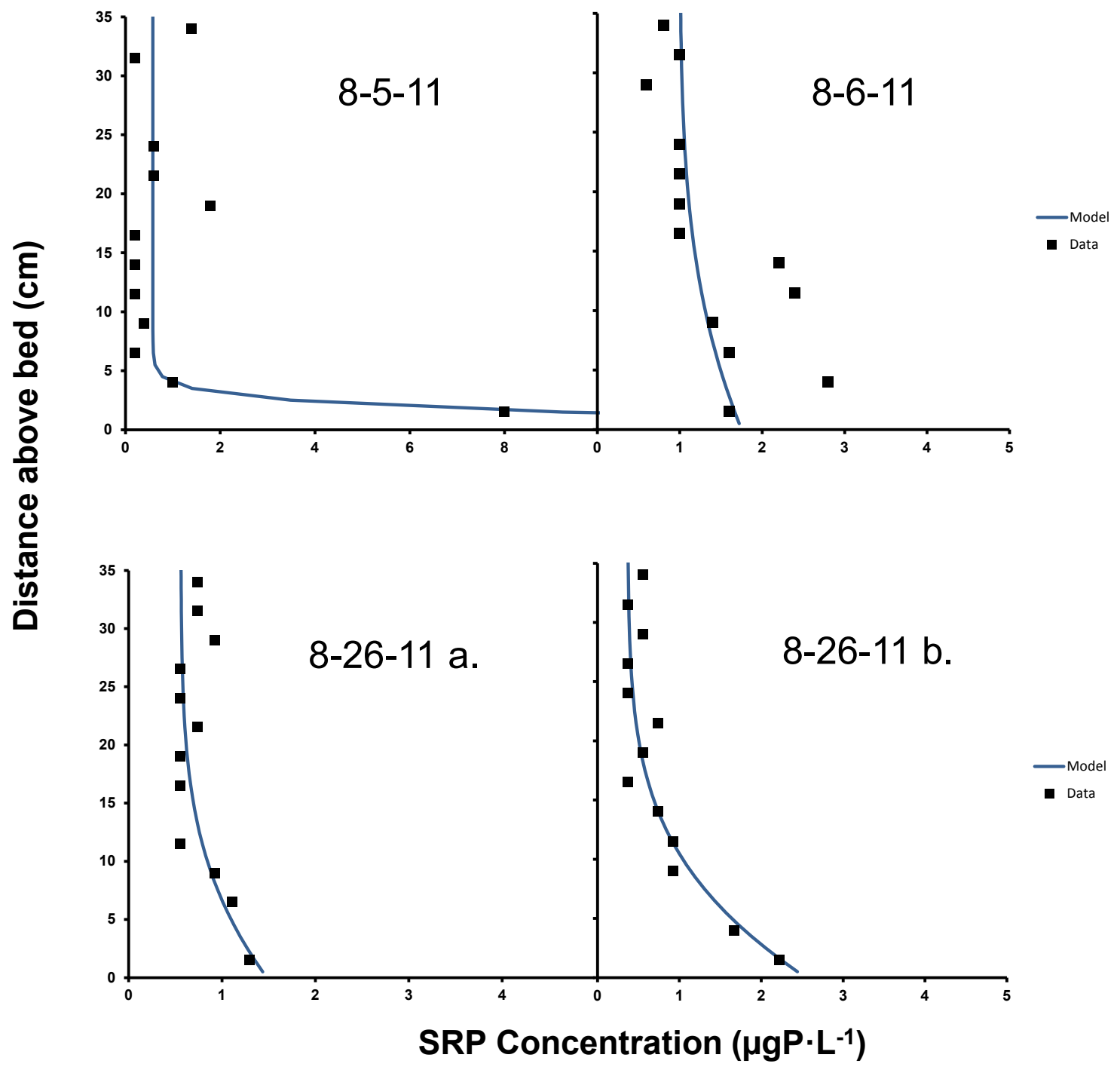

Figure 4.9: Peeper profiles calibrated to data for quiescent conditions at high mussel density locations. 


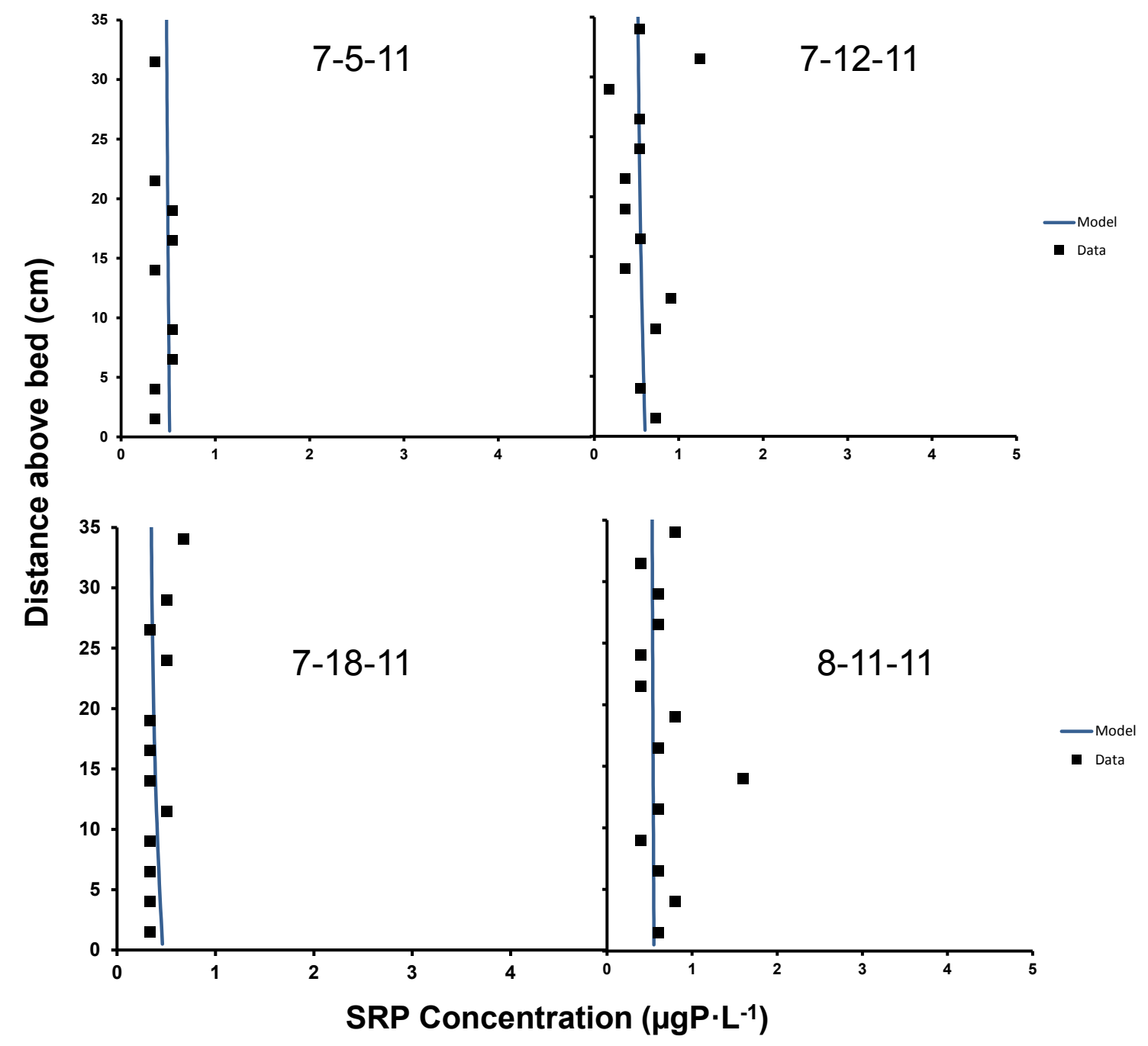

Figure 4.10: Peeper profiles calibrated to data for turbulent conditions at low and high mussel density locations. 


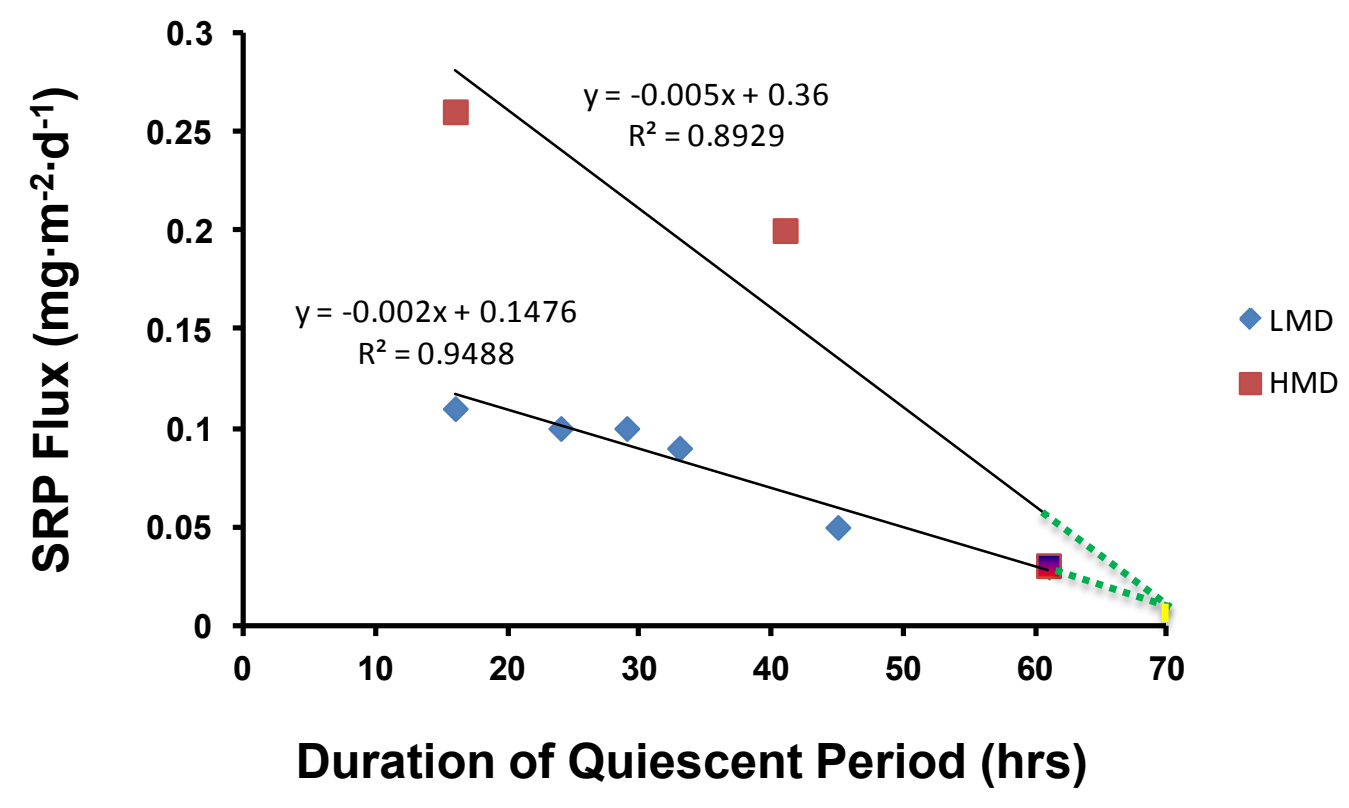

Figure 4.11: SRP flux from mussels for high and low density beds based on the duration of the quiescent period. 
the shape, e.g. compare Figure $4.9 \mathrm{a}$ to Figure $4.9 \mathrm{~d}$. A relationship between wind speed and the magnitude of $D$ as determined through calibration was thus sought.

Wind speed and direction were measured over the duration of the quiescent and turbulent periods and used to calculate a fetch-averaged velocity. The fraction of the period the winds came from each of the directions was calculated and plotted on wind roses (Figure 4.12). Due to the study site being situated in a bay, weighted averages were put on wind directions based on fetch. Winds from the northwest (coming from off the shore) received the greatest weights while winds from the southeast (coming from the shore) were weighted the least. These wind speeds were then plotted as a function of paired diffusion coefficients obtained through calibration of peeper profiles (Figure 4.13). The strong correlation obtained here provides validation of the role of wind speed and direction in mediating the nature of the concentration boundary layer and thus phosphorus levels within the zebra mussel bed. 
6-21-11

avg $=2.36 \mathrm{~m} \cdot \mathrm{s}^{-1}$ fetch avg $=0.46 \mathrm{~m} \cdot \mathrm{s}^{-1}$

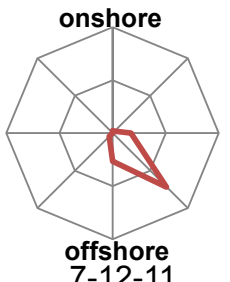

7-12-11

avg $=5.34 \mathrm{~m} \cdot \mathrm{s}^{-1}$

fetch avg. $=4.50 \mathrm{~m} \cdot \mathrm{s}^{-1}$ onshore

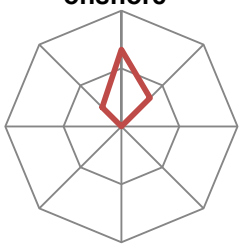

offshore
6-24-11

avg $=3.01 \mathrm{~m} \cdot \mathrm{s}^{-1}$ fetch avg. $=1.66 \mathrm{~m} \cdot \mathrm{s}^{-1}$

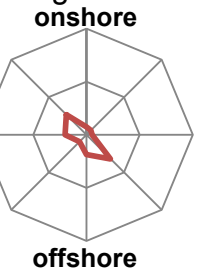

7-18-11

avg $=6.20 \mathrm{~m} \cdot \mathrm{s}^{-1}$ fetch avg. $=3.47 \mathrm{~m} \cdot \mathrm{s}^{-1}$ onshore

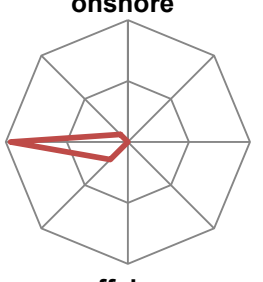

offshore
6-27-11

avg $=2.46 \mathrm{~m} \cdot \mathrm{s}^{-1}$ fetch avg. $=1.26 \mathrm{~m} \cdot \mathrm{s}^{-1}$

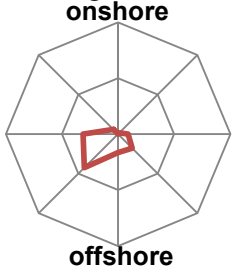

7-19-11

avg $=1.67 \mathrm{~m} \cdot \mathrm{s}^{-1}$ fetch avg. $=1.62 \mathrm{~m} \cdot \mathrm{s}^{-1}$ onshore

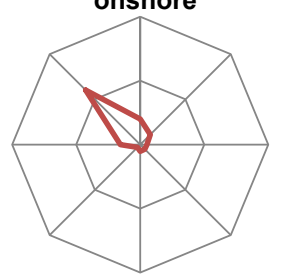

8-11-11 avg $=8.75 \mathrm{~m} \cdot \mathrm{s}^{-1}$

offshore

8-26-11 avg $=3.14 \mathrm{~m} \cdot \mathrm{s}^{-1}$ fetch avg. $=6.58 \mathrm{~m} \cdot \mathrm{s}^{-1}$ fetch avg. $=2.96 \mathrm{~m} \cdot \mathrm{s}^{-1}$ fetch avg. $=1.35 \mathrm{~m} \cdot \mathrm{s}^{-1}$

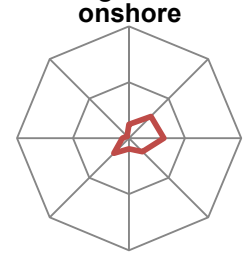

offshore

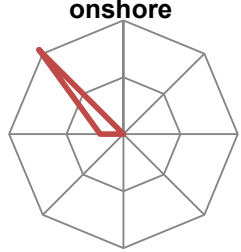

offshore

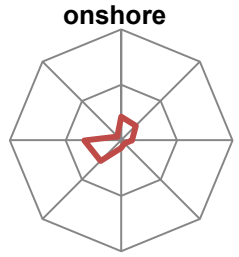

offshore
7-5-11 avg $=7.62 \mathrm{~m} \cdot \mathrm{s}^{-1}$ avg. $=6.98 \mathrm{~m} \cdot \mathrm{s}^{-1}$ onshore

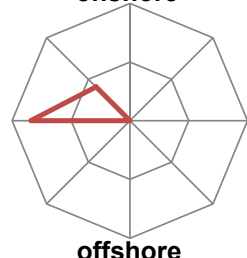

8-5-11

avg $=2.22 \mathrm{~m} \cdot \mathrm{s}^{-1}$ fetch avg. $=1.96 \mathrm{~m} \cdot \mathrm{s}^{-1}$ onshore

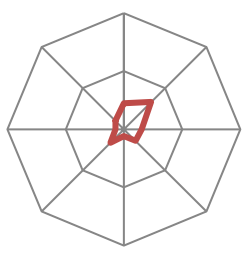

offshore

Figure 4.12. Wind roses illustrating wind direction and fetch weighted average speed throughout the duration of the quiescent or turbulent period. . 


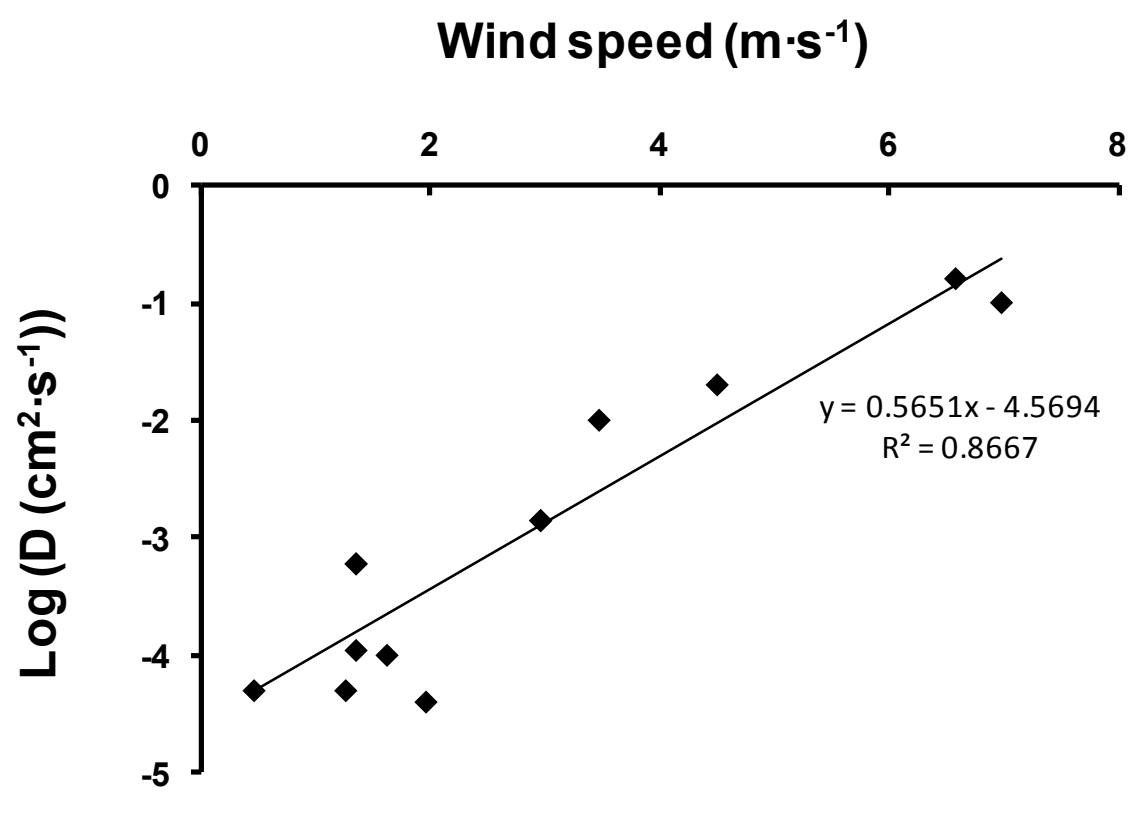

Figure 4.13: Model calibrated to the diffusion coefficient. 


\subsection{Summary, Conclusion and Implications for Management}

Peepers were used to monitor SRP concentrations above mussel beds at a site $8 \mathrm{~m}$ deep in Lake Michigan. The peepers collected water samples over a distance of $34 \mathrm{~cm}$ above the bottom in $2.5 \mathrm{~cm}$ intervals. Deployment intervals were established to capture turbulent or quiescent wind conditions that persisted for a period of time consistent with the sampler equilibration time of 7 hours. Near bottom SRP levels (5-15 $\mathrm{cm}$ above the bed) under low wind conditions ( 2$5 \mathrm{~m} \cdot \mathrm{s}^{-1}$ ) were observed to be $4-8$ times greater than those $20-34 \mathrm{~cm}$ above the bottom. Under windy conditions $\left(\geq 6 \mathrm{~m} \cdot \mathrm{s}^{-1}\right)$, no gradient was apparent, i.e. nearbottom SRP levels were not significantly different from those at a distance of 24$34 \mathrm{~cm}$ from the bottom. A vertical mass transport model was then applied to simulate the profiles forming the concentration boundary layer. The model successfully reproduced the profiles, yielding estimates for mussel flux and the diffusion coefficient.

Estimated mussel fluxes turned out to be significantly lower than those observed in the hemisphere. Since the hemisphere neglects the effect of mass transport, particulate phosphorus concentration decreases over time resulting in the observed decrease in SRP concentration which is caused by a decreasing source (PP) and an increasing sink (Cladophora uptake). Calibration supported the phenomenon that SRP flux decreased over time due to a decreasing particulate phosphorus concentration over the duration of the quiescent conditions. SRP flux estimates of previous studies using a constant a constant flux are higher than is realistic. Thus it is necessary to have a PP state variable. 
This work demonstrated phenomenologically that the character of the boundary layer depends on wind speed. As winds increased, the boundary layer became entrained leading to a relatively uniform distribution of phosphorus throughout the water column, restoring the water column profile to that of the ambient open water environment unimpacted by mussels. The thickness of the concentration boundary layer that forms under quiescent conditions and the $\mathrm{P}$ levels contained therein varied with: mussel density, wind speed, and duration of quiescent conditions.

The implication for management is that this concentration boundary layer that forms under quiescent condition, just above the mussel bed, is coincident with the portions of the water column inhabited by Cladophora $(0-15 \mathrm{~cm}$ above the mussel bed). The concentrations within this boundary layer are ecologically significant for Cladophora $\left(\geq 0.5 \mu \mathrm{gP} \cdot \mathrm{L}^{-1}\right)$. Results suggest the role of mussels in the Great Lakes has significant temporal dynamics associated with it terms of the duration of quiescent conditions and wind speeds. The time scale of Cladophora uptake of SRP is considerably different and one day of quiescence could lead to ideal conditions for Cladophora growth resulting in them being well fed for a significant amount of time. Thus a robust model would accommodate wind speed and related mixing and boundary layer dynamics and their effect on SRP uptake by Cladophora. 


\subsection{Future Work and Recommendations}

The 1D mass transport model as well as data collection improves the understanding of phosphorus mass transport in a one-dimensional direction. Future work, including collaboration with a hydrodynamicist, would allow extension of this model to a 2D advection and diffusion mass transport model which would link mussel excretion with Cladophora uptake through via the 1D mass vertical transport model. Furthermore, establishing a 3D model would require minimal additional work once the $2 \mathrm{D}$ model is formed. 


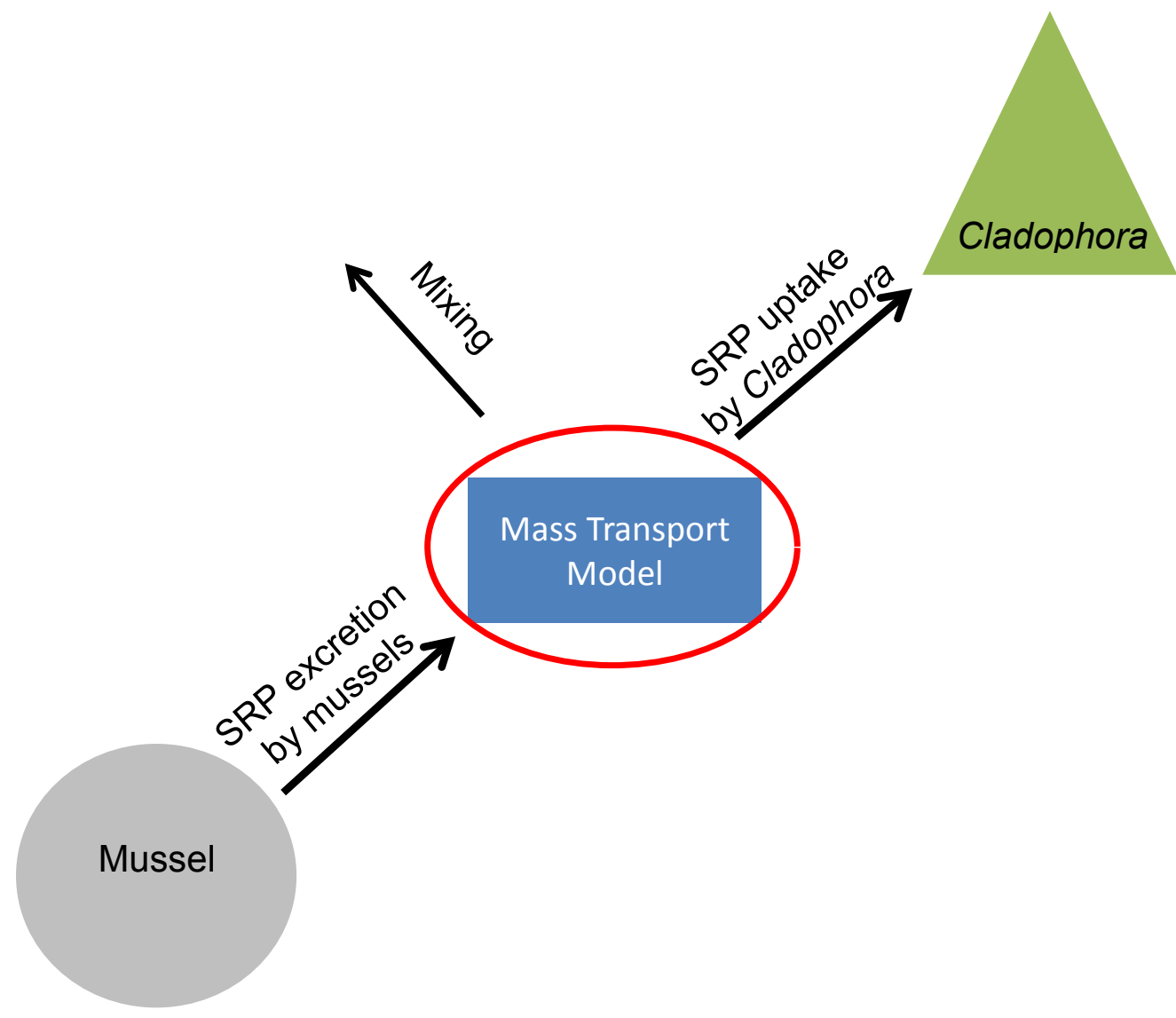

Figure 6.1: Mass transport model linking the excretion of SRP from mussels with the uptake of SRP by Cladophora. 


\subsection{References}

Ackerman JD, Loewen MR, Hamblin PF. 2001. Benthic-pelagic coupling over a zebra mussel reef in western Lake Erie. Limnology and Oceanography, 46: 892-904. Agreement Review Committee. 2006. Review of the Canada-U.S. Great Lakes Water Quality Agreement. Report to the Great Lakes Binational Executive Committee: Volume 2-Final Review Working Group Reports to ARC. U.S. EPA and Environment Canada, 449 pp.

Anderson DM, Glibert PM, Burkholder JM. 2002. Harmful algal blooms and eutrophication: nutrient sources, composition, and consequences. Estuaries. 25(4):704-726.

Arnott DL, Vanni MJ. 1996. Nitrogen and phosphorus recycling by the zebra mussel (Dreissena polymorpha) in the western basin of Lake Erie. Canadian Journal of Fisheries and Aquatic Sciences. 53(3):646-659.

Auer MT, Canale RP, Grundler HC, Matsuoka Y. 1982. Ecological studies and mathematical modeling of Cladophora in Lake Huron: 1. Program description and field monitoring. Journal of Great Lakes Research. 8(1):73-83.

Auer MT, Canale RP. 1982. Ecological studies and mathematical modeling of Cladophora in Lake Huron: 2. Phosphorus uptake kinetics. Journal of Great Lakes Research. 8(1):84-92.

Auer MT, Canale RP. 1982. Ecological studies and mathematical modeling of Cladophora in Lake Huron: 3. Dependence of growth rates on internal phosphorus pool size. Journal of Great Lakes Research. 8(1):93-99.

Auer MT, Tomlinson LM, Higgins SN, Malkin SY, Howell ET, Bootsma HA. 2010. Great Lakes Cladophora in the $21^{\text {st }}$ century: same alga-different ecosystem. Journal of Great Lakes Research. 36(2):248-255.

Boegman L, Loewen MR, Hamblin PF, Culver DA. 2008. Vertical mixing and weak stratification over zebra mussel colonies in western Lake Erie. Limnology and Oceanography. 53(3):1093-1110.

Byappanahalli MN, Shively DA, Nevers MB, Sadowsky MJ, Whitman RL. 2003. Growth and survival of Escherichia coli and enterococci populations in the macroalga Cladophora (Chlorophyta). FEMS Microbiology Ecology. 46(2):203-211. 
Canale RP, Auer MT. 1982. Ecological studies and mathematical modeling of Cladophora in Lake Huron: 7. Model verification and system response. Journal of Great Lakes Research. 8(1):134-143.

Chapra SC. 1997. Surface Water Quality Modeling. New York (NY): McGraw-Hill Publishers, $844 \mathrm{pp}$.

Charlton MN, LeSage MN, and Milne JE. 1999. Lake Erie in transition: the 1990's. pp. 97-124, In: Munawar M, Edsall T and Munawar IF (eds.), State of Lake Erie: Past, present and future. Backhuys Publishers, Leiden, the Netherlands.

Coleman FC, Williams SL. 2002. Overexploiting marine ecosystem engineers: potential consequences for biodiversity. Trends in Ecology and Evolution. 17(1):40-44.

Conroy JD, Edwards WJ, Pontius RA, Kane DD, Zhang H, Shea JF, Richey JN, Culver DA. 2005. Soluble nitrogen and phosphorus excretion of exotic freshwater mussels (Dreissena spp.): potential impacts for nutrient remineralization in western Lake Erie. Freshwater Biology. 50(7):11461162.

Depew DC, Houben AJ, Guildford SJ, Hecky RE. 2011. Distribution of nuisance Cladophora in the lower Great Lakes: Patterns with land use, near shore water quality and dreissenid abundance. Journal of Great Lakes Research. 37(4):656-671.

DePinto JV, Lam D, Auer M, Burns N, Chapra S, Charlton M, Dolan D, Kreis R, Howell T, Scavia D, Rockwell D, Bochove EV, Looby T. 1978. Examination of the status of the goals of annex 3 of the Great Lakes water quality agreement.

Dove A. 2009. Long-term trends in major ions and nutrients in Lake Ontario. Aquatic Ecosystems Health and Management. 12(3):281-295.

Dyble J, Fahnenstield GL, Litaker RW, Millie DF, Tester PA. 2008. Microcystin concentrations and genetic diversity of Microcystis in the lower Great Lakes Environmental Toxicology. 23(4):507-516.

Eaton AD, Franson MAH. (eds.) 2005. Standard Methods for the Examination of Water and Wastewater. American Public Health Association. Baltimore (MD): United BookPress, Inc. 
Fahnenstiel GL, Lang GA, Nalepa TF, Johengen TH. 1995. Effects of zebramussel (Dreissena polymorpha) colonization on water quality parameters in Saginaw Bay, Lake Huron. Journal of Great Lakes Research. 21(4):435-448.

Greb S, Garrison P, Pfeiffer S. 2004. Cladophora and water quality of Lake Michigan; a systemic survey of Wisconsin nearshore areas. Pp. 7380, In: Bootsma, H.A., Jenson, E.T., Young, E.B., Berges, J.A. (eds.), Cladophora Research and Management the Great Lakes, Proceedings of a workshop held at the Great Lakes WATER Institute, University of Wisconsin-Milwaukee, December, 2004.

Hecky RE, Smith REH, Barton DR, Guildford SJ, Taylor WD, Charlton MN. 2004. The nearshore shunt: a consequence of ecosystem engineering by dreissenids in the Laurentian Great Lakes. Canadian Journal of Fisheries and Aquatic Sciences. 61(7):1285-1293.

Higgins SN, Hecky RE, Guildford SJ. 2005. Modeling the growth, biomass, and tissue phosphorus concentration of Cladophora glomerata in eastern Lake Erie: Model description and field testing. Journal of Great Lakes Research. 31(4): 439-455.

Higgins SN, Malkin SY, Howell ET, Guildford SJ, Campbell L, Hiriart-Baer V, Hecky RE. 2008. An ecological review of Cladophora glomerata (Chlorophyta) in the Laurentian Great Lakes. Journal of Phycology. 44(4):839-854.

Higgins SN, Pennuto CM, Howell ET, Lewis T, Makarewicz JC. In review. Urban influences on Cladophora blooms in Lake Ontario. Journal of Great Lakes Research.

Holland RE. 1993. Changes in planktonic diatoms and water transparency in Hatcher Bay, Bass Island area. Western Lake Erie since the establishment of the zebra mussel. Journal of Great Lakes Research. 19(3):617-624.

Howell ET, Marvin CH, Bilyea RW, Kauss PB, Somers K. 1996. Changes in environmental conditions during Dreissena colonization of a monitoring station in Eastern Lake Erie. Journal of Great Lakes Research. 22(3):744756.

Lee GF, Jones RA, Rast W. 1980. Availability of phosphorus to phytoplankton and its implications for phosphorus management strategies. pp. 259-308. 
In: Loehr RC, Martin CS, Rast W. (eds.) Phosphorus management strategies for lakes. Ann Arbor (MI): Ann Arbor Science Publishers, Inc.

Malkin SY, Dove A, Depew D, Smith RE, Guildford SJ, Hecky RE. 2010. Spatiotemporal patterns of water quality in Lake Ontario and their implications for nuisance growth of Cladophora. Journal of Great Lakes Research. 36(3):477-489.

New York Sea Grant and Pennsylvania Sea Grant. 2001. Avian botulism in Lake Erie workshop proceedings. New York Sea Grant, University at Buffalo and Pennsylvania Sea Grant, Pennsylvania State University at Erie. 64 pp.

Ozersky T, Malkin SY, Barton DR, Hecky RE. 2009. Dreissenid phosphorus excretion can sustain C. glomerata growth along a portion of Lake Ontario shoreline. Journal of Great Lakes Research. 35(3):321-328.

Painter SD, Kamaitis G. 1987. Reduction of Cladophora biomass and tissue phosphorus in Lake Ontario, 1972-83. Canadian Journal of Fisheries and Aquatic Sciences. 44(12):2212-2215.

Taft CE, Kishler WJ. 1973. Cladophora as related to pollution and eutrophication in western Lake Erie. Water Resources Center Project Completion Report No. 332. Ohio State University, Columbus, $\mathrm{OH}$.

Tomlinson LM, Auer MT, Bootsma HA, Owens EM. 2010. The Great Lakes Cladophora Model: development, testing, and application to Lake Michigan. Journal of Great Lakes Research. 36(2):287-297.

Wilson KA, Howell ET, Jackson DA. 2006. Replacement of zebra mussels by quagga mussels in the Canadian nearshore of Lake Ontario: distribution and correlations with substrate, round goby abundance and upwelling frequency. Journal of Great Lakes Research. 32(1):11-28. 


\section{Appendix}

\section{Appendix A:}

\section{Collection of field samples}

\section{Ambient Phosphorus Measurements}

1. 2.2 Liter Van Dorn Sampler was acid washed and rinsed three times with Milli-Q water.

2. Ropes to sampler were set taught with hooks so the sampler was in the open position.

3. Sampler was deployed over side of boat to $\sim 1$ meter below the surface.

4. Messenger was sent down rope to shut the sides of the sampler.

5. Sampler was brought back up to boat

6. Hose was used to pour sample out of sampler into a previously acid washed jug.

7. Steps $2-6$ were repeated for mid (4 meters below surface) and bottom (7 meters below surface) depths.

\section{Peeper Cells}

\section{Deployment:}

Pre-deployment

1. Body and cover sheet membranes of peeper were soaked in $10 \%$ acid bath. 
2. Toothbrush was used to scrub body and membranes of peeper with acid wash.

3. Peeper parts were rinsed three times with Milli-Q water.

4. Stainless steel screws were used to attach cover sheet to 0.4 micron Sterlitech polycarbonate membranes and body of peeper.

\section{During-deployment}

1. Peeper cells were filled with Milli-Q water using a previously acid washed squirt bottle.

2. Teflon caps were inserted after the addition of Milli-Q water to each cell.

3. Peeper was deployed over the side of the boat at the study site frequently with the aid of divers.

Post-deployment

1. Peeper was retrieved from the boat (sometimes with help of divers).

2. Once on deck, teflon cap was removed.

3. Pre-acid washed glass syringe was used to extract sample from cell (Figure A.1).

4. Sample was placed in a 50-mL glass vial which included the sample's cell number.

5. Syringe was rinsed with distilled water.

a. Please note triplicate measurements of SRP was measured in all brands of distilled water several times. SRP concentrations were negligible. 


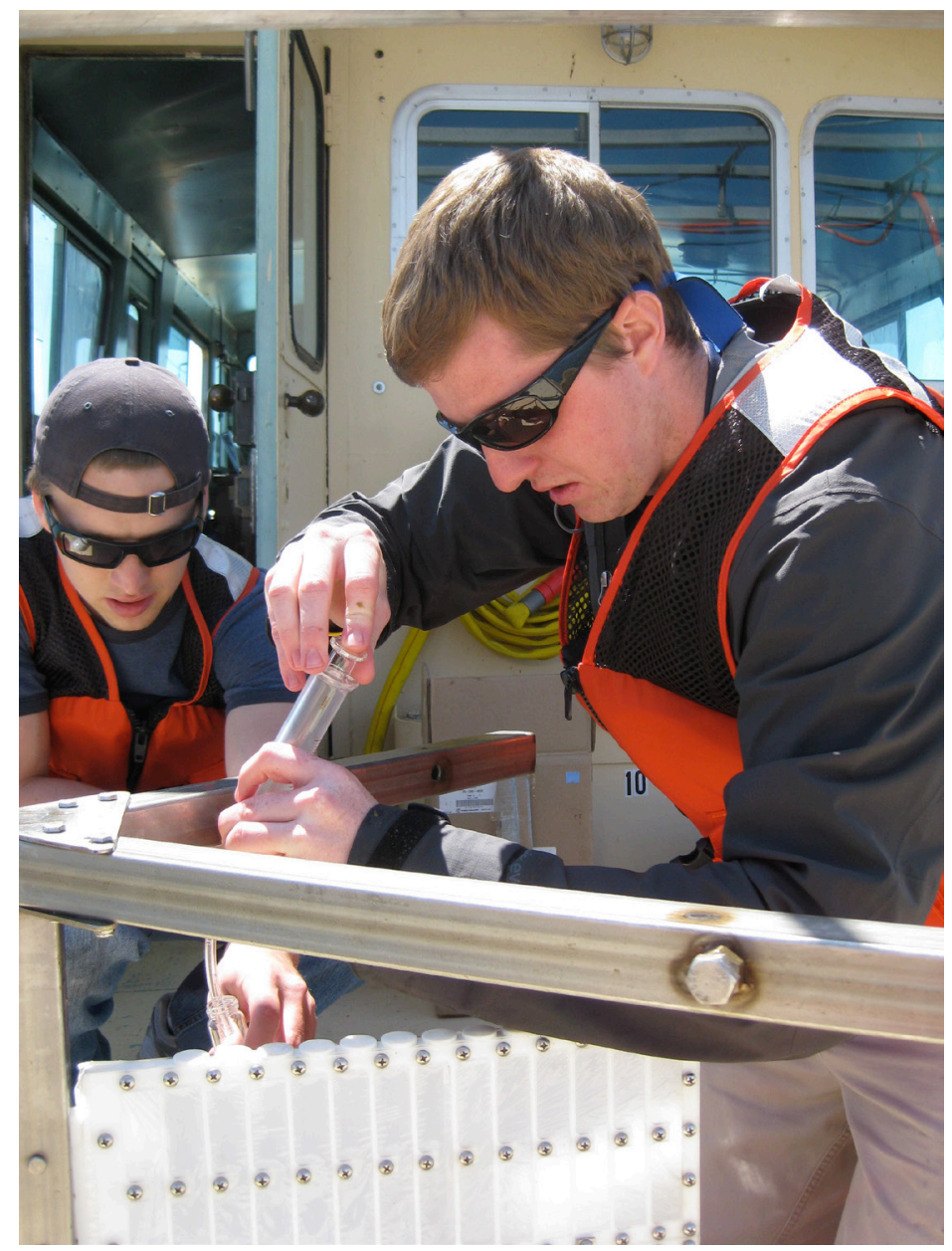

Figure A. 1: Collection of water samples from peeper. 
6. Steps $2-5$ were repeated for the remaining cells.

7. Samples were stored at $4^{\circ} \mathrm{C}$ until filtration.

\section{Filtration}

-filtering was conducted within $\sim 4$ hours of harvesting the samples.

1. Glass filter apparatus was acid washed and rinsed three times with Milli-Q water.

2. $0.45 \mu \mathrm{m}$ polycarbonate filters were placed using tweezers on filter apparatus candle and clamped down.

3. Sample was poured into filter apparatus and filtering was done at $<100$ $\mathrm{mm} \mathrm{Hg}$ ) using a vacuum pump.

4. Filter apparatus was taken apart and a pre-acid washed $25 \mathrm{~mL}$ glass volumetric pipette was used to transfer the sample to a pre-rinsed glass vial.

5. Sample was stored at $4^{\circ} \mathrm{C}$ until analysis.

6. Distilled water was poured into glass filtering apparatus.

7. Filtering Apparatus was turned on to rinse with distilled water.

8. Steps 2-7 were repeated for each of the peeper samples and for the ambient phosphorus samples.

Analysis

1. Analysis was conducted within 24 hours to measure for soluble reactive phosphorus according to the Ascorbic Acid Method (Eaton 2005) described in Appendix B. 


\section{Appendix B}

Methods for measuring Soluble Reactive Phosphorus concentrations (adapted from Ascorbic Acid Method [Eaton 2005])

\section{Preparation of Reagents}

1. Sulfuric acid, $\mathrm{H}_{2} \mathrm{SO}_{4}, 5 \mathrm{~N}$ : Dilute $70 \mathrm{~mL}$ conc $\mathrm{H}_{2} \mathrm{SO}_{4}$ to $500 \mathrm{~mL}$ with distilled water.

2. Potassium antimonyl tartrate solution: Dissolve $1.3715 \mathrm{~g}$ $\mathrm{K}(\mathrm{SbO}) \mathrm{C}_{4} \mathrm{H}_{6} \mathrm{O}_{6} \cdot 1 / 2 \mathrm{H}_{2} \mathrm{O}$ in $400 \mathrm{~mL}$ distilled water in a $500-\mathrm{mL}$ volumetric flask and dilute to volume.

3. Ammonium molybdate solution: Dissolve $20 \mathrm{~g}\left(\mathrm{NH}_{4}\right)_{6} \mathrm{Mo}_{7} \mathrm{O}_{2} 44 \mathrm{H}_{2} \mathrm{O}$ in 500 $\mathrm{mL}$ distilled water. Store in glass-stoppered bottle.

4. Ascorbic Acid, 0.1M: Dissolve $1.76 \mathrm{~g}$ ascorbic acid in $100 \mathrm{~mL}$ distilled water. The solution is stable for about 1 week at $4^{\circ} \mathrm{C}$.

5. Combined reagent: Mix the above reagents in the following poroportions for $100 \mathrm{~mL}$ of the combined reagent: $50 \mathrm{~mL} 5 \mathrm{~N} \mathrm{H}_{2} \mathrm{SO}_{4}, 5 \mathrm{~mL}$ potassium antimonyl tartrate solution, $15 \mathrm{~mL}$ ammonium molybdate solution, and 30 $\mathrm{mL}$ ascorbic acid solution. Mix after addition of each reagent. Let all reagents reach room temperature before they are mixed and mix in the order given. If turbidity forms in the combined reagent, shake and let stand for a few minutes until turbidity disappears before proceeding. The reagent is stable for $4 \mathrm{~h}$. 


\section{Procedure}

1. Add $25.0 \mathrm{~mL}$ sample into a clean, dry previously acid washed Erlenmeyer flask.

2. Add $4.0 \mathrm{~mL}$ combined reagent and mix thoroughly.

3. After at least 10 minutes, but no later than 30 minutes, measure absorbance of each sample at $880 \mathrm{~nm}$, using reagent blank as the reference solution.

\section{Preparation of calibration curve}

1. Prepare individual calibration curves from a series of six standards within the range of $0-5 \mu \mathrm{gP} \cdot \mathrm{L}^{-1}$.

2. Use a distilled water blank with the combined reagent to make photometric readings for the calibration curve.

3. Plot absorbance vs. phosphate concentration to give a straight line passing through the origin.

4. Test at least one phosphate standard with each set of samples. 


\section{Appendix C}

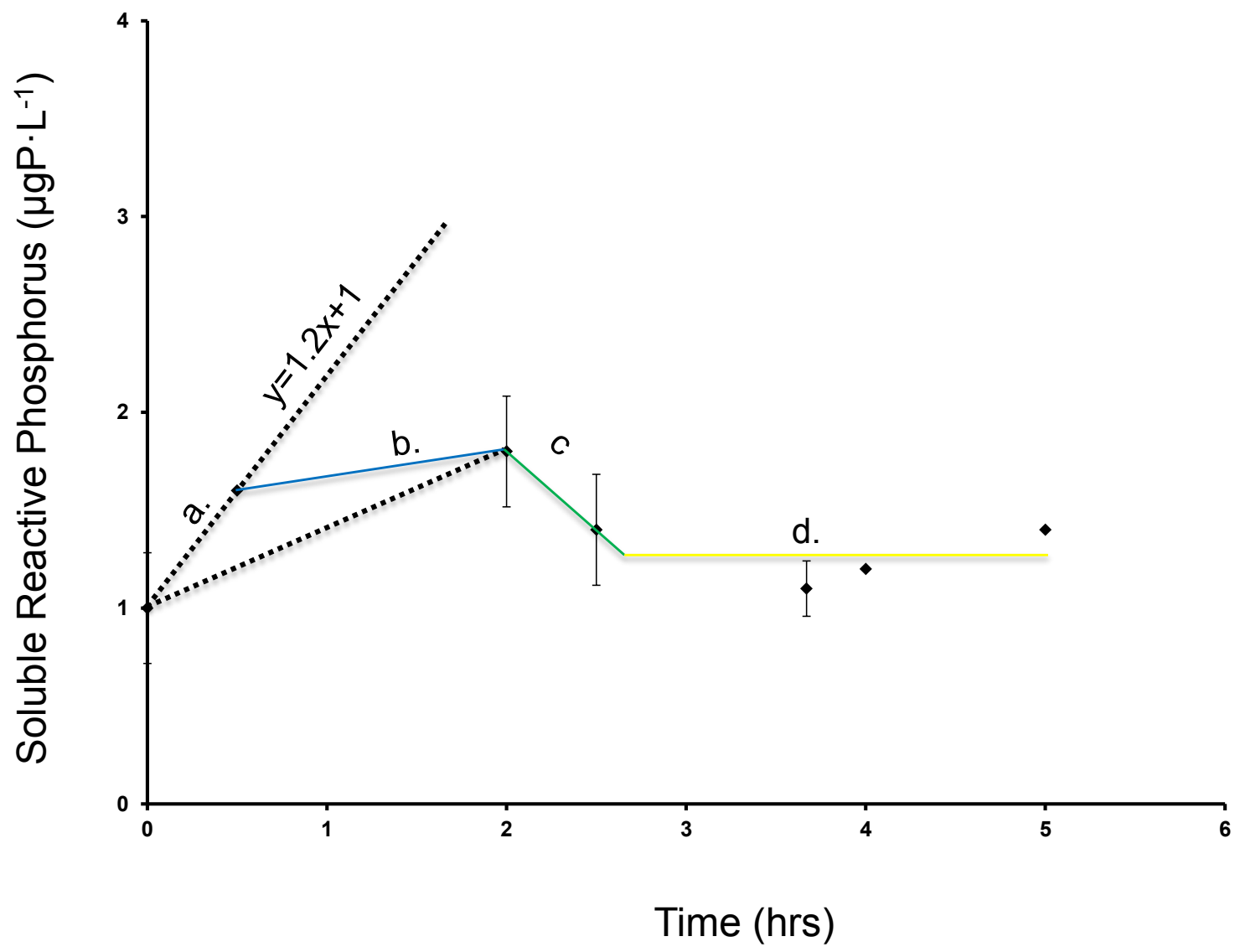

Figure 4.3: Soluble Reactive Phosphorus Concentrations over mussels surrounded by dome (Taken from text above).

1) Calculate volume of dome used in experiment

a. Volume of dome $=\pi r h^{2}-(1 / 3) \pi h^{3}$

b. $V=(0.229 m)^{*}(0.229 m)^{2}-(1 / 3)^{*}(0.229)^{3}=0.025151 m^{3}$

2) Calculate mass (M)

a. Given slope of $1.2 x$ and $\mathrm{C}_{0}=1 \mu \mathrm{gSRP} \cdot \mathrm{L}^{-1} \cdot \mathrm{hr}^{-1}$. Concentration at minute $30\left(\mathrm{C}_{30}\right)=1.6 \mu \mathrm{gSRP} \cdot \mathrm{L}^{-1} \cdot \mathrm{hr}^{-1}$.

b. $\left(1.6 \mu \mathrm{gSRP} \cdot \mathrm{L}^{-1}\right)^{*}(25.15 \mathrm{~L})-\left(1 \mu \mathrm{gSRP} \cdot \mathrm{L}^{-1}\right)^{*}(25.15 \mathrm{~L})=15.09 \mu \mathrm{gSRP} / 30$ $\min$. 
C. M / day

i. $15.09 \mu \mathrm{gSRP} / 30 \mathrm{~min} .{ }^{*} 48=724.32 \mu \mathrm{gSRP} /$ day .

3) Given M (step 2), calculate flux (F)

a. $F=M /(A)$

b. $F=724.32 \mu \mathrm{gSRP} /$ day $/\left(\left(\pi^{*} 0.229^{2}\right)\right)=4396.525 \mu \mathrm{gSRP} \cdot \mathrm{m}^{-2} \cdot \mathrm{d}^{-1}=$ $4.40 \mathrm{mgSRP} \cdot \mathrm{m}^{-2} \cdot \mathrm{d}^{-1}$. 